\title{
Marine Boundary Layer Clouds Associated with Coastally Trapped Disturbances: Observations and Model Simulations
}

\author{
Timothy W. Juliano, ${ }^{\mathrm{a}}$ MAtThew M. Coggon, ${ }^{\mathrm{b}, \mathrm{c}}$ Gregory ThOMPSON, ${ }^{\mathrm{a}}$ DAVID A. RAhn, ${ }^{\mathrm{d}}$ \\ JoHn H. SEINFELd, ${ }^{\mathrm{e}}$ ARMin SOROOSHIAN, ${ }^{\mathrm{f}, \mathrm{g}}$ AND ZACHARY J. LEBO ${ }^{\mathrm{h}}$ \\ ${ }^{a}$ Research Applications Laboratory, National Center for Atmospheric Research, Boulder, Colorado \\ ${ }^{\mathrm{b}}$ Cooperative Institute for Research in Environmental Sciences, University of Colorado Boulder, Boulder, Colorado \\ ${ }^{\mathrm{c}}$ National Oceanic and Atmospheric Administration/Earth System Research Laboratory, Boulder, Colorado \\ ${ }^{\mathrm{d}}$ Department of Geography and Atmospheric Science, University of Kansas, Lawrence, Kansas \\ e Department of Chemical Engineering, California Institute of Technology, Pasadena, California \\ ${ }^{\mathrm{f}}$ Department of Chemical and Environmental Engineering, The University of Arizona, Tucson, Arizona \\ ${ }^{\mathrm{g}}$ Department of Hydrology and Atmospheric Sciences, The University of Arizona, Tucson, Arizona \\ ${ }^{\mathrm{h}}$ Department of Atmospheric Science, University of Wyoming, Laramie, Wyoming
}

(Manuscript received 20 October 2018, in final form 24 June 2019)

\begin{abstract}
Modeling marine low clouds and fog in coastal environments remains an outstanding challenge due to the inherently complex ocean-land-atmosphere system. This is especially important in the context of global circulation models due to the profound radiative impact of these clouds. This study utilizes aircraft and satellite measurements, in addition to numerical simulations using the Weather Research and Forecasting (WRF) Model, to examine three well-observed coastally trapped disturbance (CTD) events from June 2006, July 2011, and July 2015. Cloud water-soluble ionic and elemental composition analyses conducted for two of the CTD cases indicate that anthropogenic aerosol sources may impact CTD cloud decks due to synoptic-scale patterns associated with CTD initiation. In general, the dynamics and thermodynamics of the CTD systems are well represented and are relatively insensitive to the choice of physics parameterizations; however, a set of WRF simulations suggests that the treatment of model physics strongly influences CTD cloud field evolution. Specifically, cloud liquid water path (LWP) is highly sensitive to the choice of the planetary boundary layer (PBL) scheme; in many instances, the PBL scheme affects cloud extent and LWP values as much as or more than the microphysics scheme. Results suggest that differences in the treatment of entrainment and vertical mixing in the Yonsei University (nonlocal) and Mellor-Yamada-Janjić (local) PBL schemes may play a significant role. The impact of using different driving models-namely, the North American Mesoscale Forecast System (NAM) $12-\mathrm{km}$ analysis and the NCEP North American Regional Reanalysis (NARR) 32-km products-is also investigated.
\end{abstract}

\section{Introduction}

Low marine boundary layer (MBL) clouds and fog cover a significant portion (roughly one-third) of Earth's subtropical and midlatitude oceans at any time (e.g., Jiang et al. 2014). Various communities are strongly interested in these cloud types because they influence many sectors, including naval operations, commerce and trade, biological productivity, air travel, and civilian activities, while presenting a forecasting challenge (e.g., Koračin and Dorman 2017). Moreover, these clouds and fog notably impact Earth's

Corresponding author: Timothy W. Juliano, tjuliano@ucar.edu radiation budget because they are (i) shallow and reside at low levels [relatively small longwave (LW) forcing] and (ii) more reflective than the ocean surface [relatively large shortwave (SW) forcing]; the result is a net negative cloud radiative forcing that may be similar in magnitude to that due to increasing greenhouse gases (e.g., Randall et al. 1984; Wood 2012; Boucher et al. 2013).

Here we focus on clouds that form in the cool, moist MBL, where a strong, capping subsidence inversion (on the order of $10^{\circ} \mathrm{C}$ ) separates the MBL from the warm, dry free atmosphere above (e.g., Neiburger et al. 1961; Beardsley et al. 1987). During the boreal warm season, these MBL clouds are commonly observed in 
the descending branch of the Hadley cell and over the northeast Pacific Ocean (e.g., Schubert 1976; Klein and Hartmann 1993). Due to the positions of the semipermanent Pacific high and the desert thermal low, northerly alongshore flow is a persistent feature within the MBL near the western U.S. coastline (e.g., Parish 2000).

Several times per month, the Pacific anticyclone strengthens and relocates closer to the Pacific Northwest of the United States. The flow at $850 \mathrm{hPa}$ becomes increasingly offshore near Northern California during this transition; the MBL cloud deck usually clears (e.g., Kloesel 1992; Crosbie et al. 2016), and the alongshore pressure gradient weakens. During these cases, the nearsurface wind and sea surface temperature (SST) fields go through a three-stage cycle (Fewings et al. 2016; Flynn et al. 2017) whereby the northerly flow eventually diminishes ("relaxes"). If the alongshore pressure gradient reverses, the flow becomes southerly in an event known as a coastally trapped disturbance (CTD; e.g., Dorman 1985; Mass and Bond 1996; Nuss et al. 2000; Parish et al. 2008).

Low clouds and fog often accompany CTDs as they surge northward (e.g., Bond et al. 1996; Thompson et al. 2005; Rahn and Parish 2008). For the 15-16 June 2000 case, Thompson et al. (2005) utilize numerical modeling techniques to show that a region of convergence just north of the wind shift-rather than cool SSTs-promotes cloud development. Moreover, they find that the cloud base lifts behind the CTD head as a result of cloud-top entrainment. Remote sensing observations from the 22-25 June 2006 CTD event suggest that drizzle processes develop in localized pockets (Parish et al. 2008). More recently, a synthesis of 23 CTD cases using Moderate Resolution Imaging Spectroradiometer (MODIS) observations shows that cloud properties associated with CTDs are indicative of increased aerosol loading compared to those associated with low, MBL clouds that form over the northeast Pacific under typical northerly flow conditions (Juliano et al. 2019). It is hypothesized that the fundamental difference between these two regimes is the modulation of aerosol type and number concentration by ship tracks and offshore continental flow. The result is that CTD cloud decks, which can persist for several days up to hundreds of kilometers offshore, may play a critical role in the radiation balance because they reflect more incoming SW energy $\left(\sim 6.4 \mathrm{~W} \mathrm{~m}^{-2}\right)$ than their non-CTD counterparts (Juliano et al. 2019).

In general, MBL cloud microphysical processes are amenable to aerosol perturbations. For instance, aerosol particles that are present in a supersaturated environment may activate depending on their critical supersaturation, which is a function of size and soluble mass. These activated aerosols are the fundamental sites on which clouds may form and are known as cloud condensation nuclei (CCN). Therefore, increasing the number of aerosol particles leads to an increase in $\mathrm{CCN}$ and ultimately an enhancement in cloud droplet number concentration. Small cloud droplets (particle diameter $D<50 \mu \mathrm{m}$ ) grow by condensation, and so if one assumes that a parcel maintains a constant cloud liquid water content (LWC), then an increase in the number of cloud droplets within the parcel results in a reduction in the cloud droplet effective radius $r_{e}$ and an increase in the amount of reflected incoming SW radiation (first aerosol indirect effect; Twomey 1977). Furthermore, a cloud with more numerous (and relatively small) cloud droplets is more likely to inhibit precipitation initiation and encourage persistent clouds (second aerosol indirect effect; Albrecht 1989). An overview of other proposed aerosolcloud-precipitation interactions is presented in Chen et al. (2011). Understanding these interactions is fundamental to our ability to simulate accurately the impact of MBL clouds on the climate system in global circulation models (GCMs).

A large body of work elucidates the systematic misrepresentation of MBL cloud properties by numerical models. For instance, the Weather Research and Forecasting (WRF) Model (Rahn and Garreaud 2010; Yang et al. 2011; Chen et al. 2015), Met Office Unified Model (Abel et al. 2010), and Coupled Ocean-Atmosphere Mesoscale Prediction System (Wang et al. 2011) have been shown to produce an MBL that is too shallow, especially in coastal regions. The result may be an underestimation in cloud macrophysical properties [i.e., cloud fraction and/or cloud liquid water path (LWP)]. In comprehensive studies by Wyant et al. (2010) and Wyant et al. (2015), a suite of regional, operational, and climate models underestimate cloud-top height and LWP. Furthermore, the regional models display the most variability in MBL depth. Model initialization and lateral boundary conditions (LBCs) are the suggested culprits behind the pervasive underestimation in MBL height (e.g., Andrejczuk et al. 2012).

To the authors' best knowledge, only the recent report by Juliano et al. (2019) examines specifically, aerosolcloud interactions in the context of CTDs. In the current study, we present aircraft observations from three CTD events during three different field campaigns, in addition to numerical output from WRF, to complement the aforementioned report and to address the following main goals: 
1) Characterize the various aerosol sources that may influence CTD clouds by examining backward trajectories and cloud water samples.

2) Evaluate the ability of the WRF Model to reproduce the meteorological and cloud macrophysical fields of a CTD environment using in situ and remote sensing observations.

3) Identify the sensitivity of the WRF Model results to the driving model in addition to the microphysics and planetary boundary layer (PBL) parameterizations.

The remainder of the paper is organized as follows. In section 2, the aircraft measurements, satellite retrievals, and WRF Model setup and parameterizations are described. The meteorological conditions are discussed in section 3, and the influence of synoptic-scale patterns on CTD cloud properties is presented in section 4 . Section 5 analyzes the WRF Model simulations of the case studies, and a summary and conclusions are provided in section 6 .

\section{Data and methods}

\section{a. Aircraft observations}

The three CTD cases are selected from the list of 23 CTDs analyzed in Juliano et al. (2019) due to the availability of airborne data. The CTD events and associated field projects are 22-25 June 2006 [Dynamics and Microphysics in Marine Stratocumulus (DMIMS); Parish et al. 2008; Rahn and Parish 2008, 2010], 27-29 July 2011 [Eastern Pacific Emitted Aerosol Cloud Experiment (E-PEACE); Sorooshian et al. 2018], and 16-18 July 2015 [Biological and Oceanic Atmospheric Study (BOAS); Sorooshian et al. 2018]. When referring to the individual CTD cases, we use the abbreviated project name.

DMIMS utilized the University of Wyoming King Air (UWKA), whereas both E-PEACE and BOAS utilized the Center for Interdisciplinary Remotely Piloted Aircraft Studies Twin Otter. The cruising speeds of the UWKA and Twin Otter are approximately 90 and $55 \mathrm{~m} \mathrm{~s}^{-1}$, respectively. For all three cases, we use the PVM-100A probe (Gerber et al. 1994) to retrieve cloud LWC (the probe is sensitive only to cloud droplets with $D<50 \mu \mathrm{m}$ ). To identify positively the presence of clouds in each of the three events, we use an LWC threshold of $>0.02 \mathrm{~g} \mathrm{~m}^{-3}$, similar to prior marine stratocumulus studies (e.g., Snider et al. 2017). Cloud water samples were collected during both E-PEACE and BOAS using a modified Mohnen cloud water collector (Hegg and Hobbs 1986). Each sample was then separated into multiple samples to produce $\mathrm{pH}$, water-soluble ionic composition, and water-soluble elemental composition reports (Sorooshian et al. 2018). Information about many of the major watersoluble ions and elements, whose concentrations are converted from liquid to air equivalent, are available; however, we focus on non-sea salt sulfate ${ }^{1}$ (NSS SO$\left.{ }_{4}^{2-}\right)$, nitrate $\left(\mathrm{NO}_{3}^{-}\right)$, chloride $\left(\mathrm{Cl}^{-}\right)$, ammonium $\left(\mathrm{NH}_{4}^{+}\right)$, silicon $(\mathrm{Si})$, manganese $(\mathrm{Mn})$, and iron

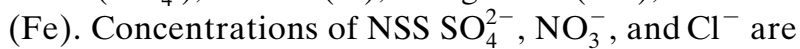
used to examine chloride depletion due to anthropogenic sources, while those of $\mathrm{NH}_{4}^{+}, \mathrm{Si}, \mathrm{Mn}$, and $\mathrm{Fe}$ reveal the potential impact of various continental sources on CTD clouds.

Aircraft maneuvers differed between DMIMS and E-PEACE/BOAS. Because one of the main goals of the DMIMS CTD case was to map the atmospheric pressure field, the two main UWKA flight strategies included isobaric and sawtooth tracks. The former involved long, straight legs that followed an isobaric surface, while the latter incorporated vertical porpoising maneuvers along a straight leg to capture a two-dimensional picture of the pressure field and associated meteorology. The porpoising method yielded slant vertical profiles. During E-PEACE and BOAS, the two main Twin Otter flight techniques included vertical ladder patterns from near the sea surface to just above cloud top and stair-step patterns along a straight leg. Both slant and spiral vertical profiles were also conducted. A schematic of the E-PEACE and BOAS flight patterns may be found in Sorooshian et al. (2018).

We examine observations from the following dates and corresponding campaign research flights (RFs) due to in situ data availability and spatial coverage: 24 June 2006 (DMIMS), 26-29 July 2011 (RF13-RF16; E-PEACE), and 17 July 2015 (RF11; BOAS). The relevant flight tracks and cloud water sampling locations from which we present data are plotted in Fig. 1.

\section{b. Spaceborne measurements}

We also utilize satellite retrievals from MODIS to compare measured and modeled cloud physical properties. Here, we use retrievals of cloud-top $r_{e}$ and optical thickness $\tau$ at $3.7 \mu \mathrm{m}$, as in Juliano et al. (2019), to calculate cloud LWP. For the MODIS analysis, we consider a retrieval or model grid box cloudy if $L W P \geq 10 \mathrm{~g} \mathrm{~m}^{-2}$.

\section{c. WRF Model setup}

The nested two-domain structure used for all of the WRF simulations is shown in Fig. 2. Horizontal grid spacing in the

\footnotetext{
${ }^{1}$ To remove the sulfate that is tied up in pure sea salt and isolate the $\mathrm{SO}_{2}$-derived sulfate, NSS sulfate is calculated using the ratio of sulfate to sodium in pure seawater (e.g., Seinfeld and Pandis 2006).
} 


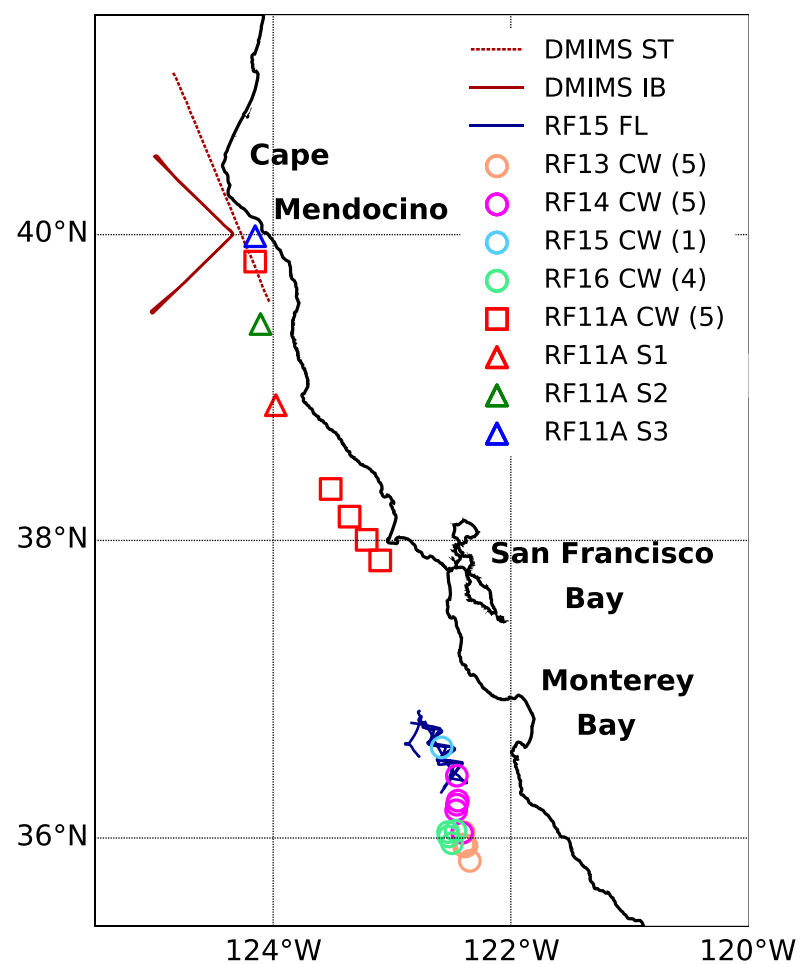

FIG. 1. Region of interest with markers that represent the in situ aircraft observation locations that are used to evaluate WRF. The DMIMS vertical sawtooth (ST) and isobaric (IB) flight tracks from 24 Jun 2006 are shown by the dashed and solid dark red lines, respectively. The E-PEACE RF15 (28 Jul 2011) flight legs (FL) are shown by the solid dark blue line. Vertical profiles during spirals 1,2 , and 3 (S1, S2, and S3) from BOAS RF11A (17 Jul 2015) are shown by the red, green, and blue triangles, respectively. Cloud water (CW) samples from RF13, RF14, RF15, and RF16 during E-PEACE, and RF11A during BOAS, are indicated by the light salmon, magenta, light sky blue, and light green circles, and red squares, respectively. The number of CW samples that were collected on a particular day is shown in parentheses.

outer (d01) and inner (d02) domains are 3 and $1 \mathrm{~km}$, respectively, with the number of grid points in the $x$ and $y$ directions equal to 400 (546) and 546 (804) for d01 (d02), respectively. We employ adaptive time stepping (target Courant-Friedrichs-Lewy condition of 1.2); the typical time steps for the outer and inner domains are 6 and $2 \mathrm{~s}$, respectively. There are 83 vertical eta levels ${ }^{2}$ for both domains. The vertical grid spacing is $\sim 10 \mathrm{~m}$ in the lowest $500 \mathrm{~m}$ and stretches thereafter. The simulations for DMIMS, E-PEACE,

\footnotetext{
${ }^{2}$ To alleviate the computational expense of using a large number of vertical levels, new modeling techniques, such as the Framework for Improvement by Vertical Enhancement (FIVE; Yamaguchi et al. 2017), may be incorporated in future efforts in which resolving strong vertical gradients is desired.
}

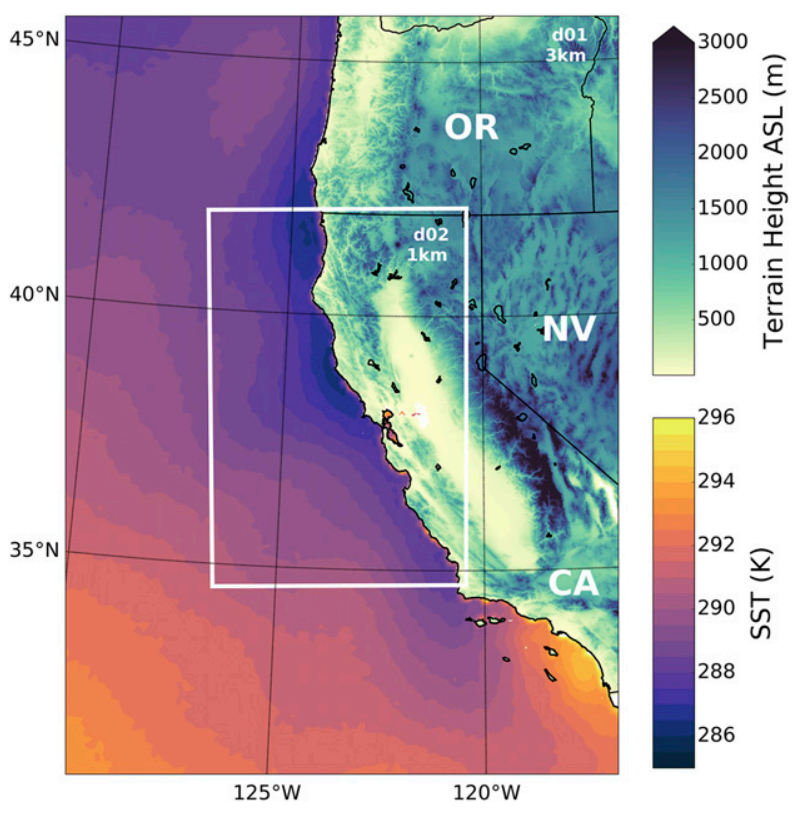

FIG. 2. The WRF domain configuration with the outer (d02; $3-\mathrm{km}$ horizontal grid spacing) and inner (d01; 1-km horizontal grid spacing) domains shown. Terrain height ( $\mathrm{m} \mathrm{MSL}$ ), in addition to mean sea surface temperature (SST; K) for the three CTD cases, are color contoured with corresponding color bars. Relatively cool SSTs near the coastline signify the persistent upwelling regions due to strong, northerly flow at low levels. State abbreviations are also shown for reference: Oregon (OR), Nevada (NV), and California (CA).

and BOAS begin at 0000 UTC 22 June 2006, 0000 UTC 26 July 2011, and 0000 UTC 15 July 2015, respectively, and output once per hour. The DMIMS and BOAS simulations are run for three days, and the E-PEACE simulations are run for four days. All simulations use the Rapid Radiative Transfer Model for GCMs (RRTMG) LW and SW radiation parameterizations (Iacono et al. 2008) and the Noah land surface model (Tewari et al. 2004). A cloud fraction parameterization based on Mocko and Cotton (1995) following Sundqvist et al. (1989) was recently incorporated into WRF and is employed here (icloud $=3$ ).

A series of simulations with various model configurations are conducted to compare with the observations (Table 1). We focus on the impact of the driving model [see the appendix for details about the impact of initial conditions (ICs) versus LBCs], as well as the PBL and microphysics parameterizations, on the CTD cloud evolution. Specifically, we compare the influence of forcing by the North American Mesoscale Forecast System (NAM) 12-km analysis and the NCEP North American Regional Reanalysis (NARR) $32-\mathrm{km}$ products. We anticipate 
TABLE 1. The various WRF Model simulation configurations used in this study.

\begin{tabular}{cclc}
\hline \hline $\begin{array}{c}\text { Simulation (Driving } \\
\text { Model_Microphysics_PBL) }\end{array}$ & $\begin{array}{c}\text { Driving } \\
\text { Model }\end{array}$ & Microphysics & PBL \\
\hline NARR_M_Y & NARR & Morrison & YSU \\
NARR_M_M & NARR & Morrison & MYJ \\
NARR_T_Y & NARR & Thompson & YSU \\
NARR_T_M & NARR & Thompson & MYJ \\
NAM_M_Y & NAM & Morrison & YSU \\
NAM_M_M & NAM & Morrison & MYJ \\
NAM_T_Y & NAM & Thompson & YSU \\
NAM_T_M & NAM & Thompson & MYJ \\
\hline
\end{tabular}

that the mesoscale cloud properties in WRF will be sensitive to the forcing grids because NARR is relatively coarser than NAM, and the two forcing sources use different assimilation schemes (Mesinger et al. 2006; Wang 2010). Moreover, the number of vertical levels interpolated to the WRF domains is 30 and 40 for NARR and NAM, respectively. The vertical grid spacing is $25 \mathrm{hPa}$ from 1000 to $50 \mathrm{hPa}$ for $\mathrm{NAM}$ and $25 \mathrm{hPa}$ from 1000 to $100 \mathrm{hPa}$ (with the exception of 700 to $300 \mathrm{hPa}$, where the vertical grid spacing is $50 \mathrm{hPa}$ ) for NARR. This interpolation procedure, which likely leads to a poor representation of the lower-tropospheric structure, may influence the relatively shallow clouds that are modeled in this study.

For the parameterizations, we evaluate the Yonsei University (YSU; Hong et al. 2006) and MellorYamada-Janjić (MYJ; Janjić 1994) PBL schemes in addition to the Morrison (Morrison et al. 2005) and Thompson (Thompson et al. 2008) microphysics schemes. After examining the in situ aircraft data for the three cases simulated herein, we find that using a cloud droplet number concentration $N_{c}$ of $150 \mathrm{~cm}^{-3}$ in the model is appropriate.

\section{1) PBL PARAMETERIZATIONS}

The first-order, nonlocal closure YSU scheme identifies the PBL height as the level where the buoyancy flux, which is a function of $\theta_{v}$ and the bulk Richardson number, is a minimum (e.g., Kim and Yum 2017). In WRF, this particular PBL treatment is unique because it explicitly calculates the entrainment rate $w_{e}$ at the inversion layer

$$
w_{e}=\frac{\overline{\left(w^{\prime} \theta_{v}^{\prime}\right)_{h}}}{\left.\Delta \theta_{v}\right|_{h}},
$$

where $\overline{\left(w^{\prime} \theta_{v}^{\prime}\right)_{h}}$ is the heat flux for moist air at the inversion layer (Moeng and Sullivan 1994) and $\left.\Delta \theta_{v}\right|_{h}$ is the change in virtual potential temperature across the inversion layer. Perhaps not surprising, entrainment increases as relatively warm air is fluxed downward into the BL [numerator in Eq. (1)] and/or the inversion strength decreases [denominator in Eq. (1)]. The numerator in Eq. (1) is expressed as

$$
{\overline{\left(w^{\prime} \theta_{v}^{\prime}\right)_{h}}}_{=}=-0.15\left(\frac{\theta_{v a}}{g}\right) w_{m}^{3} / h,
$$

and the term $w_{m}$ is represented as

$$
w_{m}^{3}=w_{*}^{3}+5 u_{*}^{3},
$$

where the first and second terms on the rhs of Eq. (3) are the mixed-layer velocity scale for dry air and the surface friction velocity, respectively. The terms in Eq. (3) indicate that the inversion-layer heat flux, and ultimately $w_{e}$, is a function of both surface and columnar BL processes.

Unlike the YSU scheme, the MYJ scheme is a 1.5order, local closure whereby TKE is treated prognostically, and the PBL height is estimated as the level where TKE is a minimum (e.g., Kim and Yum 2017). Therefore, the MYJ approach does not explicitly calculate $w_{e}$.

We emphasize that the manner in which each scheme mixes vertically within the BL is fundamentally different. Within the YSU scheme, BL scalars (heat, mass, and moisture) that characterize a particular layer are allowed to mix with all other vertical layers within the BL. This nonlocal approach is designed to replicate mixing by large-scale eddies whose length scale may be approximately equal to the BL depth. In comparison, the MYJ scheme allows BL scalars to mix with only the adjacent layers. This local method suggests that small-scale eddies are responsible for most of the vertical mixing. As will be addressed later, we hypothesize that the shallow, MBL cloud decks found in the three cases are sensitive to this fundamental difference in vertical mixing approaches.

\section{2) MICROPHYSICS PARAMETERIZATIONS}

Owing to our large horizontal model grid spacing relative to cloud processes, microphysics must be parameterized. For the warm clouds (cloud-top temperature greater than $0^{\circ} \mathrm{C}$ ) modeled here, important processes include aerosol activation, droplet growth by vapor diffusion, autoconversion, accretion, selfcollection, breakup, and sedimentation. Because the Morrison and Thompson schemes use different techniques to represent moist processes, a brief description of each treatment now follows. 
The Morrison scheme is a bulk microphysical parameterization, which means that the distribution of liquid water (and all other hydrometeor species) is represented by a continuous function (e.g., gamma or exponential) that depends on the mass mixing ratio and $N_{c}$ (Morrison et al. 2005). Moreover, it is single moment for cloud (cloud water mixing ratio is predicted, but $N_{c}$ is fixed) and double moment for rainwater, ice, snow, and graupel (both mass and number are predicted). To determine when cloud water vapor condenses, the Morrison scheme uses a polynomial approximation to resolve explicitly supersaturation from temperature and water vapor mixing ratio $q_{v}$ (Morrison et al. 2005). Prognostic aerosol is not considered in this particular version, and so when a model grid box is cloudy, $N_{c}$ is instantly equal to the predefined user value $\left(150 \mathrm{~cm}^{-3}\right.$ in the case here as altered from the default setting of $250 \mathrm{~cm}^{-3}$ ). Parameterizations of autoconversion and accretion follow the approach of Khairoutdinov and Kogan (2000), while the self-collection of rain follows Beheng (1994). The breakup of rain follows a modified version of Verlinde and Cotton (1993), and the rain evaporation parameterization comes from Rutledge and Hobbs (1983).

Similar to the Morrison scheme, the Thompson scheme is a bulk microphysical parameterization; however, it is considered partially double moment, whereby only mass is predicted for cloud water, snow, and graupel, but both mass and number are predicted for rainwater and ice (Thompson et al. 2008). Because ice physics is not important in the CTD events, the doublemoment snow/graupel treatment in Morrison versus the single-moment treatment in Thompson is effectively immaterial for these simulations. Similar to the Morrison scheme, $N_{c}=150 \mathrm{~cm}^{-3}$ (altered from the default setting of $100 \mathrm{~cm}^{-3}$ ) in a cloudy grid box. Additionally, the Thompson scheme calculates the saturation threshold using a polynomial expansion and the Newton-Raphson method is used to handle supersaturation adjustment (Thompson et al. 2008). Thompson uses a modified version of Berry and Reinhardt (1974) to parameterize autoconversion. One unique feature of the Thompson schemes is that accretion is calculated following the collection equation described by Verlinde et al. (1990). Here, the collection efficiency is a function of the size of the collector (rain drop) and collected (cloud droplet) species. Rain self-collection, breakup, and evaporation follow Beheng (1994), Verlinde and Cotton (1993), and Srivastava and Coen (1992), respectively. While the Morrison and Thompson schemes use the same rain self-collection and breakup basis, their implementations differ slightly on threshold (trigger) of mean size and prefactor for the rate equation.

\section{d. Comparing aircraft measurements to WRF output}

For the flight tracks during the DMIMS (constantpressure surface) and E-PEACE (constant-altitude surface) CTD cases, the WRF Model is evaluated as follows. First, the 1-Hz aircraft observations are spatially (temporally) averaged to match the WRF output from d02 (11 and 18 observation points from DMIMS and E-PEACE, respectively). Next, the horizontal $[(x, y)]$ model grid box closest to each aircraft observation is found. At each of these $(x, y)$ locations, the two closest vertical grid boxes are found and averaged. After iterating over all observation locations, the data and model output are binned and compared using histograms. For BOAS, aircraft vertical soundings are compared to WRF by averaging all of the $(x, y)$ model grid boxes that the airplane intersects during its spiral. The number of $(x, y)$ grid boxes used in the average for spirals 1,2 , and 3 (S1, S2, and S3) are 9, 7, and 7, respectively. The WRF output file with time closest to that of the mean aircraft leg is used for comparison, and if the time of the mean aircraft leg is between 20 and $40 \mathrm{~min}$ past the hour, then we average the two closest WRF output files. This procedure is also used to evaluate WRF against the MODIS retrievals.

Evaluating a numerical simulation using aircraft data that are on a constant pressure or altitude surface is challenging because one cannot assume that the model is reproducing spatiotemporal properties of the atmosphere with fidelity. When comparing the UWKA measurements to the WRF output for DMIMS, we normalize the altitude by cloud-top height for three reasons: 1) the CTD cloud deck during this case is characterized by cloud tops that are much lower than those during E-PEACE and BOAS, 2) isobaric flight legs are conducted relatively close to cloud top, and 3) WRF simulates a much shallower-than-observed MBL. If we do not normalize the altitude, then the altitude in the model is above the MBL, where the atmosphere is much warmer and drier (i.e., devoid of any cloud).

For the DMIMS evaluation, we use the PVM100A LWC probe observations to estimate a cloudtop height of $250 \mathrm{~m}$ above mean sea level (MSL) and assume that the cloud extends to the ocean surface (resulting in a cloud depth $H$ of $250 \mathrm{~m}$ ). Radar observations (not shown) suggest that cloud base is below the lowest altitude range gate ( $\sim 50 \mathrm{~m} \mathrm{MSL})$. Our results are mostly insensitive to changing the cloud depth to $200 \mathrm{~m}$ (cloud-base height of $50 \mathrm{~m}$ MSL). Moreover, while there is diurnal variability, 


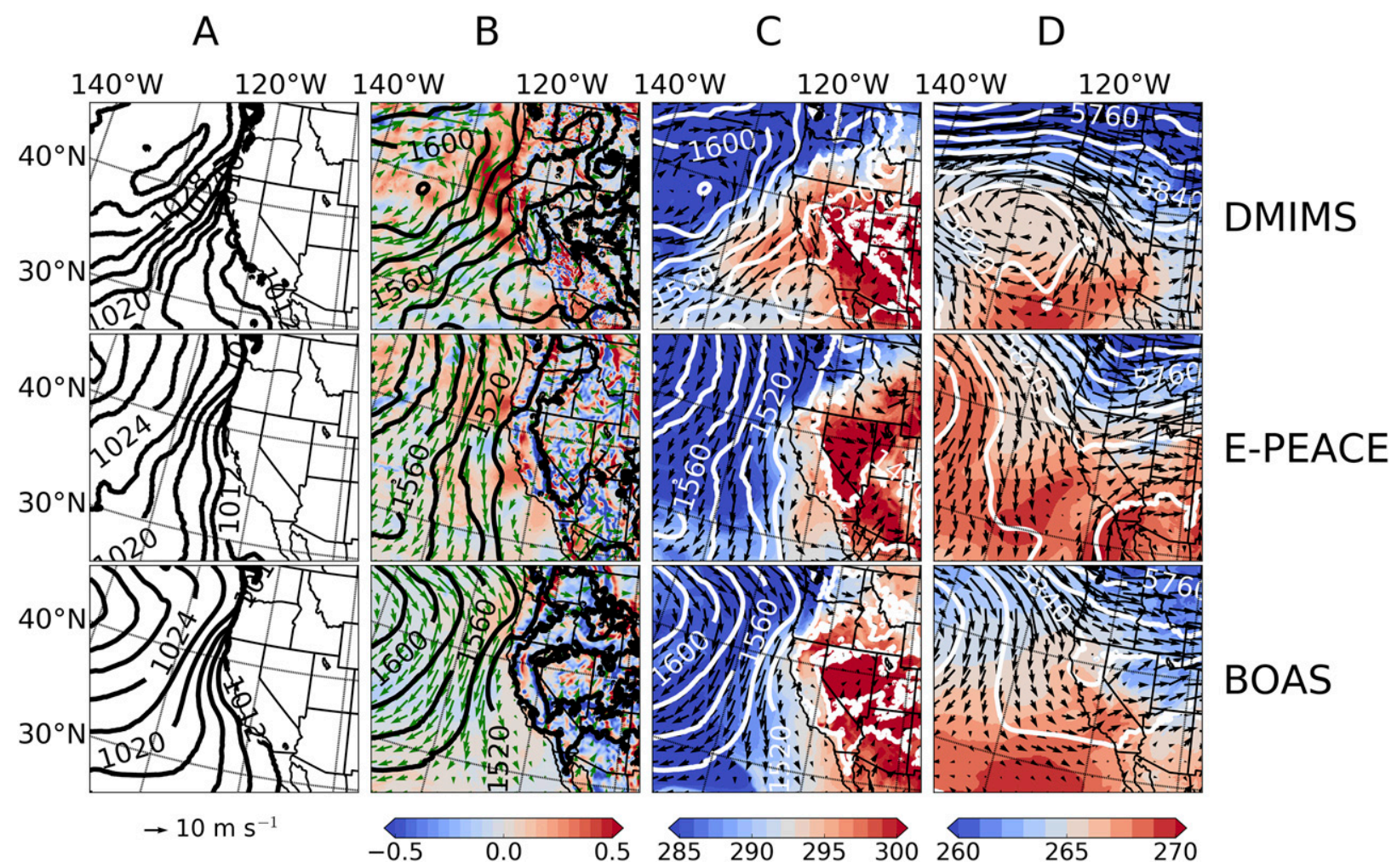

FIG. 3. The 0000 UTC 12-km NAM grids for day 0 (22 Jun 2006, 27 Jul 2011, and 16 Jul 2015) during (top) DMIMS, (middle) E-PEACE, and (bottom) BOAS. (a) Sea level pressure (SLP; black contours; hPa). (b) 850-hPa height (black contours; $\mathrm{m}$ ), wind arrows, and vertical velocity (color contoured with color bar; $\mathrm{Pa} \mathrm{s}^{-1}$ ). (c) 850-hPa height (white contours; $\mathrm{m}$ ), wind arrows, and temperature (color contoured with color bar; K). (d) 500-hPa height (white contours; m), wind arrows, and temperature (color contoured with color bar; K).

the WRF simulations for this case indicate that cloud base extends to the surface in many locations near the coastline (not shown).

\section{Meteorological conditions}

It is important to consider the synoptic-scale weather conditions that characterize each CTD event because the large-scale forcing significantly impacts the macrophysical (e.g., $H$ and LWP) properties, and likely the microscale characteristics, of the stratiform cloud decks. Figures 3 and 4 show NAM 12-km analysis grids and NARR 32-km grids, respectively, for sea level, $850 \mathrm{hPa}$, and $500 \mathrm{hPa}$ at $0000 \mathrm{UTC}$ on the CTD initiation day (day 0: 22 June 2006, 27 July 2011, and 16 July 2015) for each event (DMIMS, E-PEACE, and BOAS). All three cases show that the Pacific high is anomalously strong and positioned farther north and east compared to climatology, as shown in Juliano et al. (2019). The strongest nearshore sea level pressure (SLP) gradient is present during the DMIMS case. Moreover, the DMIMS SLP isobars are oriented northeast to southwest, whereas the E-PEACE and BOAS SLP isobars are oriented more north-northeast to south-southwest. Both the NAM Pacific high and the NAM cross-shore SLP gradient are stronger than NARR for DMIMS and BOAS and weaker than NARR for E-PEACE. Offshore flow and subsequent descending motion (subsidence) at $850 \mathrm{hPa}$ are present in all cases; however, they are most intense during the DMIMS case (vertical velocity exceeding $+0.5 \mathrm{~Pa} \mathrm{~s}^{-1}$ in some offshore regions), as $850-\mathrm{hPa}$ warm temperature anomalies extend hundreds of kilometers offshore. Subsidence is slightly stronger during E-PEACE compared to BOAS. NAM and NARR show generally similar values of subsidence. At $500 \mathrm{hPa}$, there is little difference between NAM and NARR. The general flow is quite similar between E-PEACE and BOAS, with the upper-level high pressure well offshore and confluent flow near the San Diego region. In contrast, the Pacific high is located just offshore California during DMIMS. The differences in synoptic-scale offshore flow between DMIMS and E-PEACE/BOAS likely play an integral role in modulating the capping temperature inversion above the MBL. The offshore flow down the topography, which is associated with both warm air advection over the ocean 


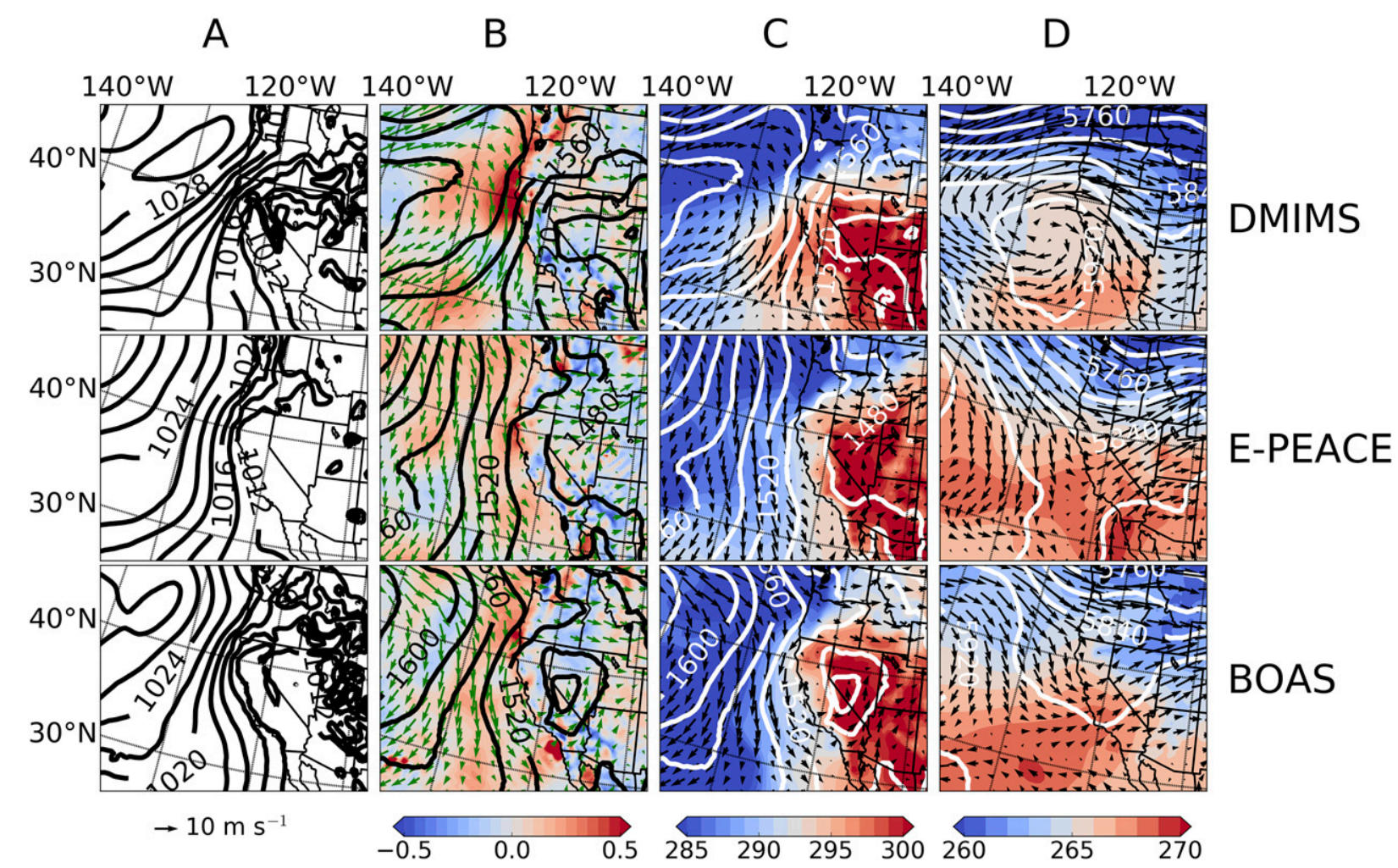

FIG. 4. As in Fig. 3, but for the 0000 UTC 32-km NARR grids.

and subsidence warming above the MBL (Mass and Steenburgh 2000), can lead to differences in cloud properties such as $H$ and LWP, and cloud processes such as entrainment.

Geostationary Operational Environmental Satellite (GOES) visible imagery and surface NAM 12-km grids are plotted for the lifetime of each CTD (Fig. 5). Overall, the SLP field is similar in all three cases, but the gradient is slightly tighter for DMIMS, while E-PEACE and BOAS show similar pressure gradients; this is confirmed by the surface winds, which show generally stronger winds for DMIMS. Perhaps not surprising, the lowest pressure is found along the central California coastline. The cloud fields are notably different between the three cases. For DMIMS, on day 0 , the CTD cloud deck is farthest south and tied closest to the coast. Also, there are no clouds to the west. The most plausible explanation is that extraordinarily warm and dry air from the continent erode the MBL and promote excessive entrainment outside of the CTD system (cf. Figs. 3 and 4). Clouds are present in nearly the entire domain for E-PEACE with the exception of a small region of cloud clearing that is most likely associated with offshore flow and subsidence (cf. Figs. 3 and 4). The cloud deck in BOAS looks similar to E-PEACE; however, there are fewer clouds to the north and west of the main CTD system. Moreover, finescale structure is present in all cloud fields, with a stratiform to stratocumulus transition evident (e.g., Wood 2012) toward the south.

Over the next couple of days, the SLP field and cloud deck for each case evolve quite differently. For instance, the DMIMS cloud deck appears to progress northward the most while maintaining a distinct cloud field that is attached to the southerly surge. Due to the shear zone that exists on the westward edge of the wind reversal, a well-defined cyclonic eddy develops on day 1. Ultimately, by day 2 , the mesoscale pressure field prevents each of the cloud decks from propagating farther northward.

\section{Synoptic-scale influence on CTD cloud properties}

A main finding from the study by Juliano et al. (2019) suggests that CTD cloud decks are typically composed of more cloud droplets than non-CTD cloud decks due to the influence of both shipping emissions and continental sources and their interaction with sea salt. We utilize the Hybrid Single-Particle Lagrangian Integrated Trajectory model (HYSPLIT; Stein et al. 2015) to examine the extent to which each of the three events 


\section{DMIMS}
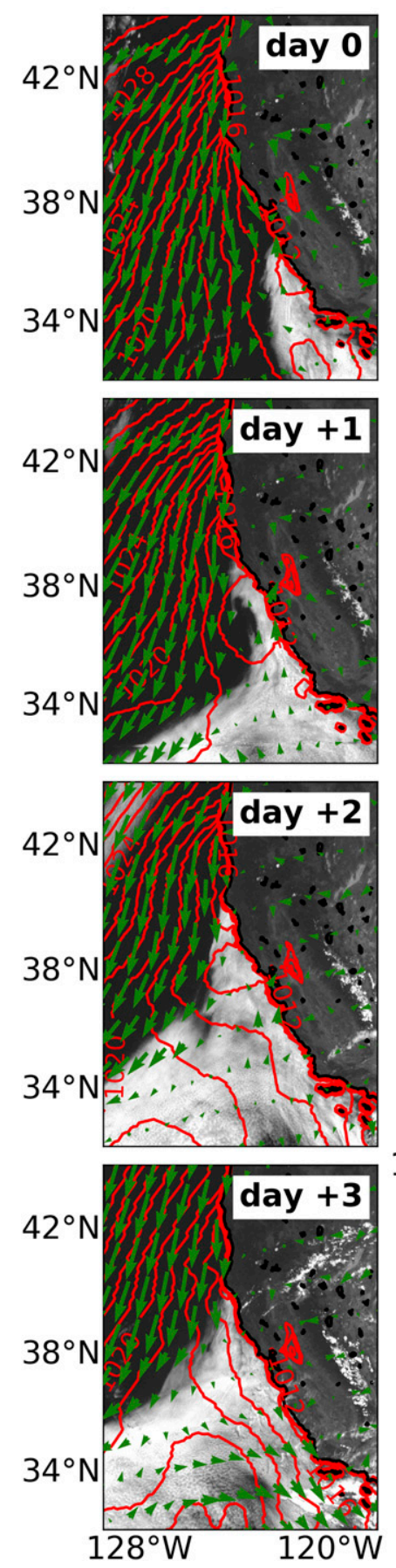

\section{E-PEACE BOAS}
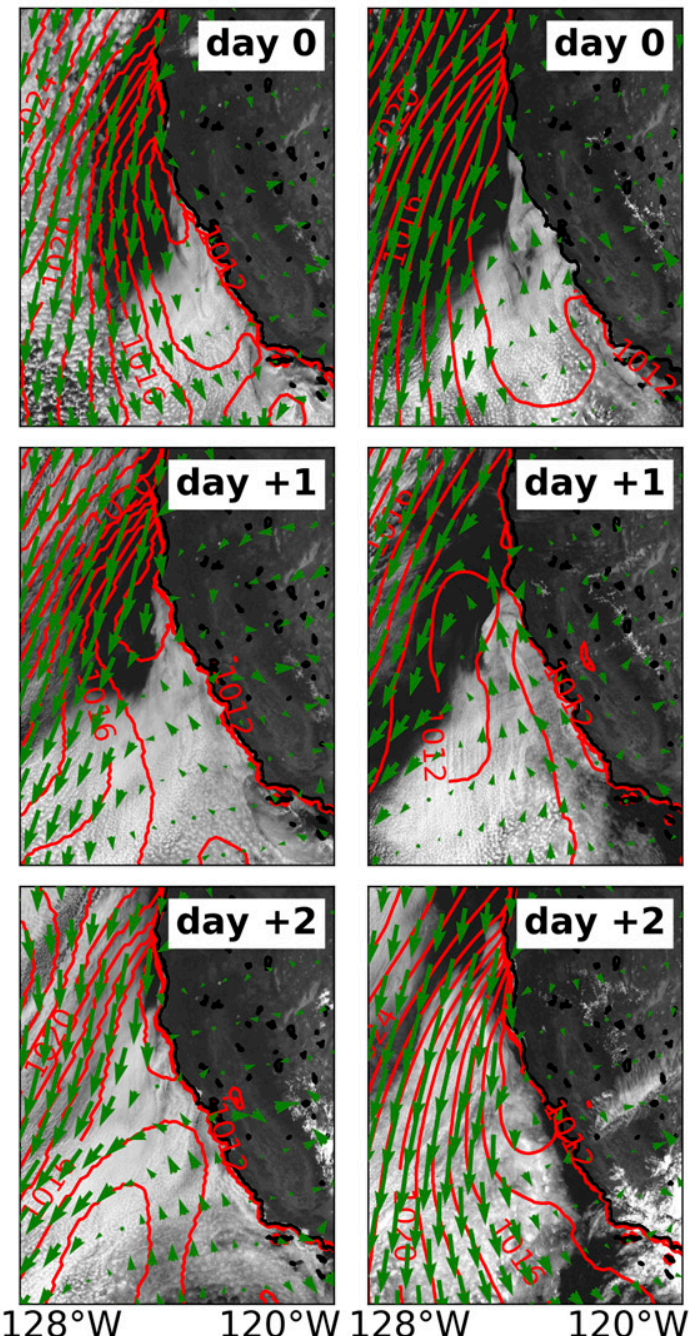

FIG. 5. CTD evolution for (left) DMIMS, (center) E-PEACE, and (right) BOAS as depicted by Geostationary Operational Environmental Satellite (GOES) visible imagery and NAM $12-\mathrm{km}$ grids. The $10-\mathrm{m}$ wind arrows (green) and SLP contours (red) are shown. Day 0 is 22 Jun 2006, $27 \mathrm{Jul}$ 2011, and $16 \mathrm{Jul} 2015$ during DMIMS, E-PEACE, and BOAS, respectively. GOES images and NAM grids are from $\sim 1930$ and 1800 UTC, respectively. examined here may be influenced by the aforementioned continental sources (Fig. 6). The 72-h matrix backward trajectories are initialized with the NAM $12-\mathrm{km}$ analysis grids at 0000 UTC on day +1 (23 June 2006, 28 July 2011, and 17 July 2015, respectively) to accurately represent the interaction between continental air and the CTD cloud deck. For backward trajectories ending at $100 \mathrm{~m}$ (Fig. 6, top row), their airmass origins are predominantly from the remote Pacific Ocean prior to traversing along the coastline; however, for those ending at $1000 \mathrm{~m}$ (Fig. 6, bottom row), all three events show evidence of significant 


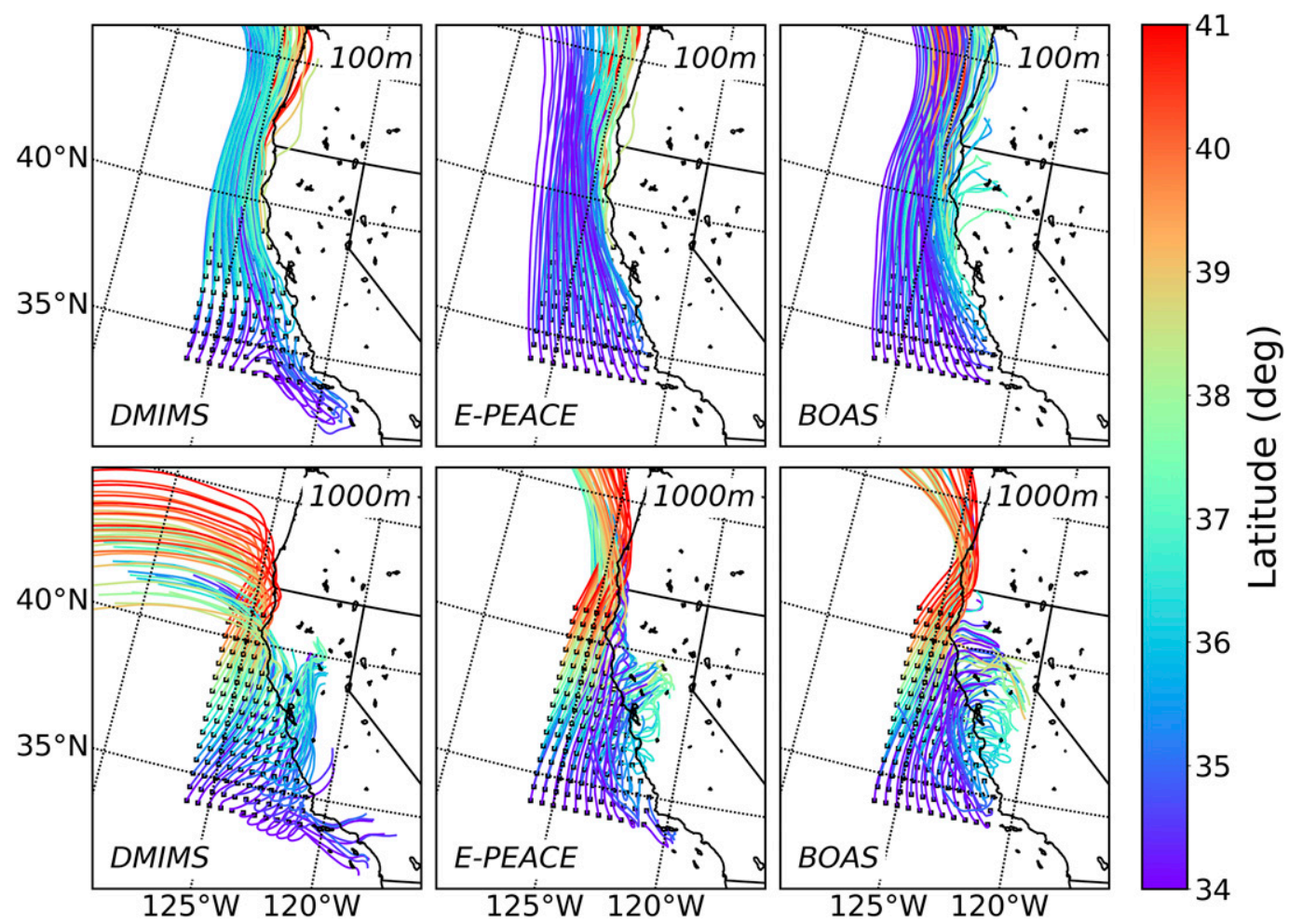

FIG. 6. HYSPLIT 72-h backward trajectories for the (left) DMIMS, (center) E-PEACE, and (right) BOAS CTD cases ending at (top) 100 and (bottom) $1000 \mathrm{~m}$ MSL at 0000 UTC on day +1 (23 Jun 2006, 28 Jul 2011, and 17 Jul 2015). The NAM 12-km analysis grids are used to initialize the model. Trajectory paths are color coded with the color bar according to initialization latitude $\left(^{\circ}\right)$.

continental influence. ${ }^{3}$ While continental plumes affect nearly all latitudes, the largest influence is seen from approximately $35.0^{\circ}$ to $37.5^{\circ} \mathrm{N}$. Continental air may extend to $\sim 500 \mathrm{~km}$ offshore (mainly at lower latitudes). Trajectories pass over nearly all of the source regions ${ }^{4}$ identified by Juliano et al. (2019): (i) ship tracks (within $\sim 100 \mathrm{~km}$ from the coastline; e.g., see Fig. 9 in Coggon et al. 2012), (ii) urbanized (Los Angeles, San Francisco Bay Area, San Jose, and Sacramento), (iii) biogenic (forests in Northern California and Oregon), and (iv) agricultural

\footnotetext{
${ }^{3}$ Continental aerosol residing above the MBL are important due to their radiative impact (direct effect; e.g., Yu et al. 2006; Mardi et al. 2018) and subsequent influence on thermal stability, which affects MBL cloud evolution (semidirect effect; e.g., Ackerman et al. 2000; Amiri-Farahani et al. 2017).

${ }^{4}$ We use retrievals from the Cloud-Aerosol Lidar with Orthogonal Polarization (CALIOP) for all three CTD cases, measurements from a Droplet Measurement Technologies (DMT) Single Particle Soot Photometer (SP2) for the E-PEACE case, and data from the Fire Inventory (FINN) from the National Center for Atmospheric Research (NCAR) for the BOAS case to conclude that wildland fire activity in California and Oregon was minimal or nonexistent during the three cases. Therefore, biomass-burning influence on CTD clouds may be neglected for these particular cases.
}

(Sacramento Valley and San Joaquin Valley). We may expect the in situ aerosol and chemistry aircraft measurements to support the hypothesis that ship tracks and polluted continental air influence the CTD cloud decks.

Cloud water samples collected during E-PEACE (82 total: RF1-RF30 sans RF3, RF7, RF27A, RF27B, RF27C, RF29B, RF30A, and RF30B) research flights provide valuable information that may help determine aerosol source regions. We now focus on NSS sulfate, nitrate, and chloride, which are composited and summarized for all E-PEACE samples in Fig. 7. These data are contrasted with those from day -1 (RF13) through day +2 (RF16). On day -1 , proportions of NSS sulfate, nitrate, and chloride are very similar to the mean E-PEACE proportions; however, the sum of the concentrations from these three ions are nearly half of the campaign mean. The samples on this day are from nonCTD clouds because the CTD is south of the sampling locations and the wind direction is still northerly (not shown). Samples from day 0 to day +2 (RF14-RF16) are all within the CTD because the wind direction is southerly (not shown). As the event progresses, higher concentrations of NSS sulfate and nitrate are measured; the highest concentrations of nitrate from all samples during the E-PEACE 

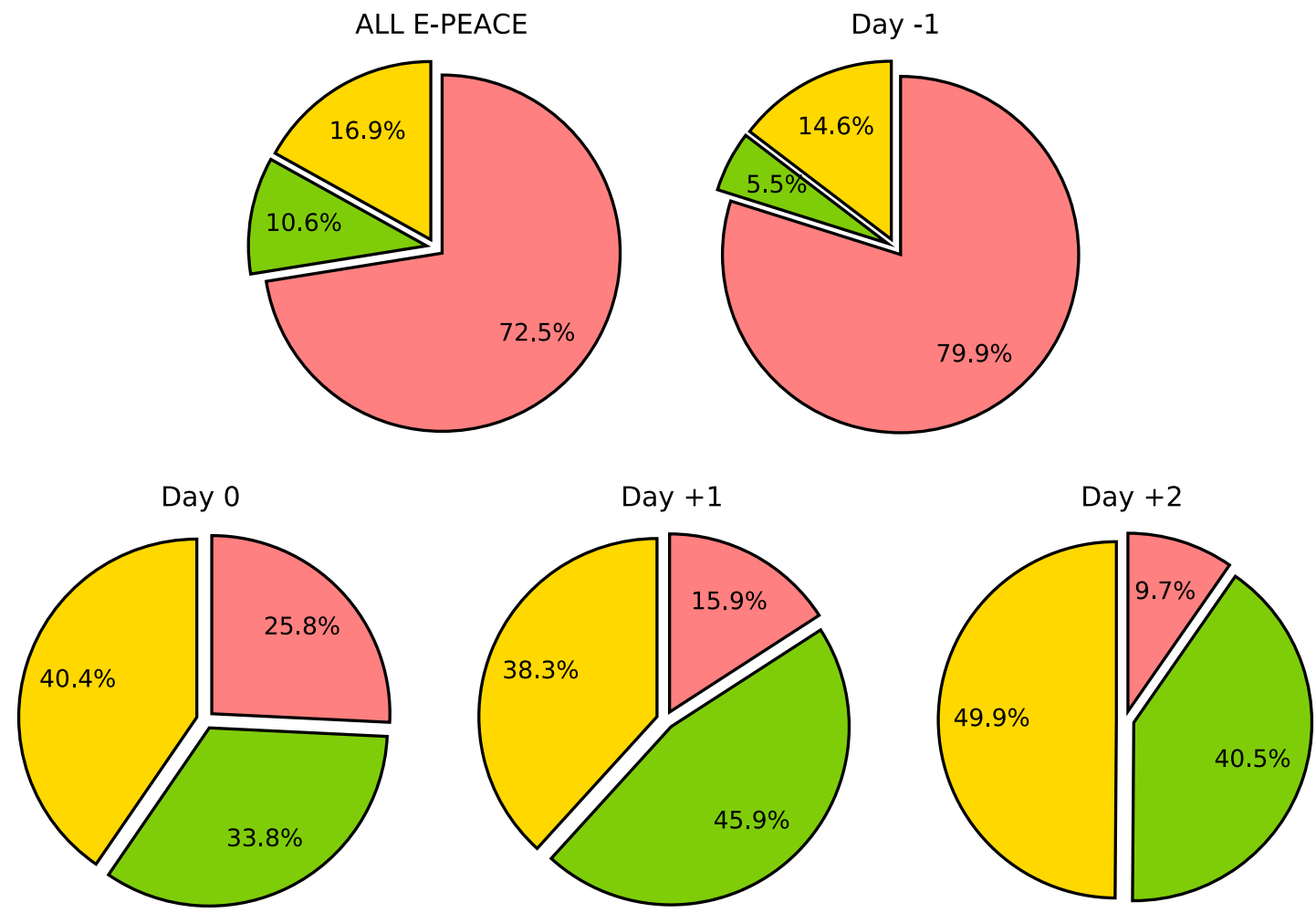

\begin{tabular}{|l|r|r|r|r|r|}
\cline { 2 - 6 } \multicolumn{1}{c|}{} & All $(\mathrm{n}=82)$ & Day $-1(\mathrm{n}=5)$ & Day 0 $(\mathrm{n}=5)$ & Day $+1(\mathrm{n}=1)$ & Day $+2(\mathrm{n}=4)$ \\
\hline $\begin{array}{l}\text { NSS Sulfate }\left(\mu \mathrm{g} \mathrm{m}^{-3}\right) \\
\text { NSS Sulfate }(\%)\end{array}$ & $\begin{array}{r}1.0(<0.1-2.9) \\
(<0.1-64.1)\end{array}$ & $\begin{array}{r}0.5(0.4-0.6) \\
(10.2-20.3)\end{array}$ & $\begin{array}{r}1.5(1.2-1.8) \\
(28.8-46.5)\end{array}$ & $\begin{array}{r}2.6 \\
38.3\end{array}$ & $\begin{array}{r}2.7(2.5-2.9) \\
(46.2-51.4)\end{array}$ \\
\hline $\begin{array}{l}\text { Nitrate }\left(\mu \mathrm{g} \mathrm{m}^{-3}\right) \\
\text { Nitrate }(\%)\end{array}$ & $\begin{array}{r}0.6(0.1-3.1) \\
(1.7-48.1)\end{array}$ & $\begin{aligned} 0.2(0.1-0.3) \\
(4.3-6.3)\end{aligned}$ & $\begin{array}{r}1.3(1.0-1.5) \\
(28.9-39.2)\end{array}$ & $\begin{array}{r}3.1 \\
45.9\end{array}$ & $\begin{array}{r}2.2(2.1-2.4) \\
(38.7-44.2)\end{array}$ \\
\hline $\begin{array}{l}\text { Chloride }\left(\mu \mathrm{g} \mathrm{m}^{-3}\right) \\
\text { Chloride }(\%)\end{array}$ & $4.3(<0.1-21.3)$ & $\begin{array}{r}2.5(1.5-4.6) \\
(73.7-84.2)\end{array}$ & $\begin{array}{r}1.0(0.6-1.7) \\
(14.2-42.4)\end{array}$ & $\begin{array}{r}1.1 \\
15.9\end{array}$ & $\begin{array}{r}0.5(0.5-0.6) \\
(9.1-10.1)\end{array}$ \\
\hline
\end{tabular}

FIG. 7. Pie charts showing proportions of NSS sulfate (gold), nitrate (yellow-green), and chloride (light coral) ions in cloud water samples collected during the E-PEACE campaign. "ALL-E-PEACE" shows the mean proportions for all samples during the campaign, while "Day -1," "Day 0," "Day +1," and "Day +2" refer to the days (RF13, RF14, RF15, and RF16, respectively) relative to the E-PEACE CTD case. Summary statistics are shown in the table: mean (minimum-maximum) concentrations $\left(\mu \mathrm{g} \mathrm{m}^{-3}\right)$ and (minimum-maximum) proportions $(\%)$ are shown for each ion and day. Note that there is no range of values for Day +1 because there is only one water sample.

field project are actually found in the RF15 sample. Moreover, a reduction in chloride is present, whereby the ion proportion decreases considerably over time.

The E-PEACE RF14-RF16 flight days are examined by Coggon et al. (2012). They find significant enhancements in below-cloud sulfate, which are predominantly affected by shipping exhaust. Additionally, in these samples, they observe enhancements in vanadium, which is a marker for shipping emissions ${ }^{5}$ (e.g., Agrawal

\footnotetext{
${ }^{5}$ Recent work suggests that vanadium may not be an appropriate tracer for ships using marine diesel oil due to its low sulfur content (Xiao et al. 2018).
}

et al. 2008; Furutani et al. 2011). Backward trajectories for the RF14-RF16 flights show that the cloud water samples likely pass through the major shipping lanes prior to sampling, which is different for cleaner periods when the flow originates predominantly from the remote marine atmosphere (Coggon et al. 2012).

During the E-PEACE and Nucleation in California Experiment (NiCE) studies, nitrate enhancements were mostly from ship emissions and biomass burning (Prabhakar et al. 2014); however, agricultural regions represent another possible nitrate source. To probe the potential advection of agricultural byproducts into the CTD cloud decks, we examine cloud water 

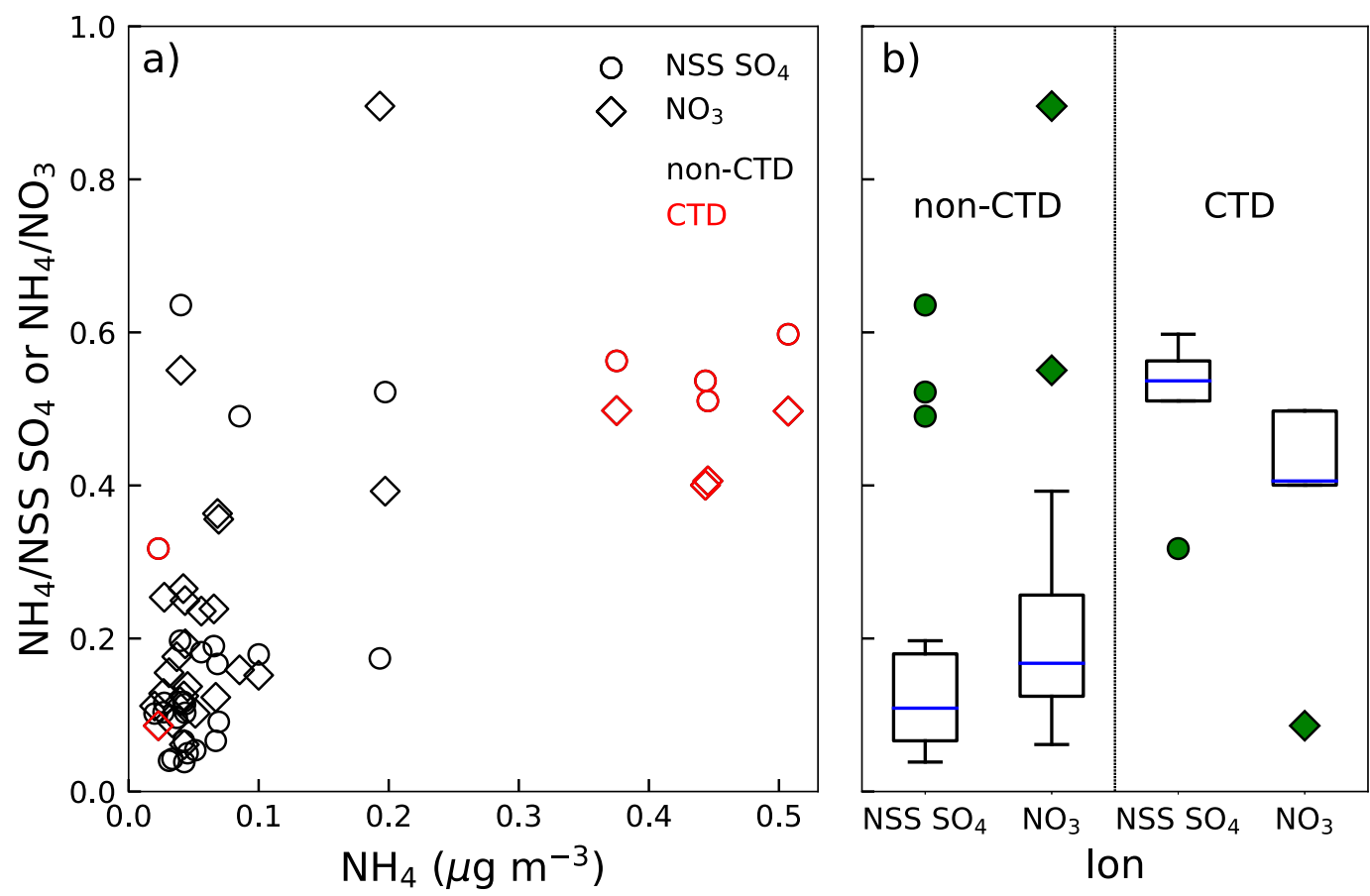

FIG. 8. (a) Scatterplot of ammonium $\left(\mathrm{NH}_{4}\right)$ concentration $\left(\mu \mathrm{g} \mathrm{m}^{-3}\right)$ vs ammonium to NSS sulfate $\left(\mathrm{NH}_{4} / \mathrm{NSS}\right.$ $\left.\mathrm{SO}_{4}\right)$ and ammonium to nitrate $\left(\mathrm{NH}_{4} / \mathrm{NO}_{3}\right)$ mass ratios for all cloud water samples during the BOAS campaign. Samples collected on non-CTD and CTD days are colored black and red, respectively. Also, $\mathrm{NH}_{4} / \mathrm{SO}_{4}\left(\mathrm{NH}_{4} / \mathrm{NO}_{3}\right)$ ratios are shown by the circles (diamonds). (b) Box-and-whisker plots showing the $\mathrm{NH}_{4} / \mathrm{SO}_{4}$ and $\mathrm{NH}_{4} / \mathrm{NO}_{3}$ mass ratios during non-CTD and CTD cases. In each plot, the blue line represents the median value, while the box represents the 25 th and 75 th percentiles. Also, the whiskers extend to the 10 th and 90 th percentiles, and the green markers represent outliers.

$\mathrm{NH}_{4}^{+}$concentrations from BOAS (Fig. 8). The largest value from all samples during BOAS is seen during the CTD: the mean concentrations for all samples during BOAS and for RF11A during BOAS are 0.11 and $0.36 \mu \mathrm{g} \mathrm{m}^{-3}$ (range of $0.02-0.51 \mu \mathrm{g} \mathrm{m}^{-3}$ ), respectively. These results may indicate that there is at least some influence from areas rich with ammonia $\left(\mathrm{NH}_{3}\right.$; e.g., agricultural fertilizers). When ammonia is present, it may react with sulfuric acid $\left(\mathrm{H}_{2} \mathrm{SO}_{4}\right)$ and nitric acid $\left(\mathrm{HNO}_{3}\right)$ to yield ammonium sulfate $\left[\left(\mathrm{NH}_{4}\right)_{2} \mathrm{SO}_{4}\right]$ and ammonium nitrate $\left(\mathrm{NH}_{4} \mathrm{NO}_{3}\right)$ :

$$
\begin{gathered}
\mathrm{H}_{2} \mathrm{SO}_{4}(g)+2 \mathrm{NH}_{3}(a q)=\left(\mathrm{NH}_{4}\right)_{2} \mathrm{SO}_{4}(s), \\
\mathrm{HNO}_{3}(g)+\mathrm{NH}_{3}(a q)=\mathrm{NH}_{4} \mathrm{NO}_{3}(s) .
\end{gathered}
$$

Coggon et al. (2012) hypothesize that enhancements in $\mathrm{Fe}$ and $\mathrm{Mn}$ metals in offshore cloud water samples during RF14-RF16 may be due to the advection of air masses from nearby continental sources. Vertical profiles of cloud water $\mathrm{Si}, \mathrm{Fe}$, and $\mathrm{Mn}$ during RF14-RF16 of E-PEACE and RF11A of
BOAS are compared with the E-PEACE and BOAS campaign mean values, respectively (Fig. 9). These metal ions come from mineral sources that make up dust aerosol and may indicate a continental influence on MBL clouds. $\mathrm{Fe}$ is especially prevalent in these minerals (e.g., hematite and goethite), and the same is true, though to a lesser degree, for Mn. Figure 9 shows that $\mathrm{Si}, \mathrm{Fe}$, and $\mathrm{Mn}$ concentrations generally increase over time during E-PEACE. During RF16 of EPEACE and RF11A of BOAS, values for all three metals are quite large-especially $\mathrm{Mn}$ and $\mathrm{Fe}-$ indicating that there is likely a continental influence on these cloud water samples. Overall, the concentration enhancements range from about 2 to 5 times the mean campaign values.

As sulfuric acid or nitric acid reacts with sodium chloride $(\mathrm{NaCl})$, the chloride is liberated as a gas and only sodium sulfate $\left(\mathrm{Na}_{2} \mathrm{SO}_{4}\right)$ or sodium nitrate $\left(\mathrm{NaNO}_{3}\right)$ remain:

$$
\begin{gathered}
\mathrm{H}_{2} \mathrm{SO}_{4}(g)+2 \mathrm{NaCl}(a q)=2 \mathrm{HCl}(g)+\mathrm{Na}_{2} \mathrm{SO}_{4}(a q), \\
\mathrm{HNO}_{3}(g)+\mathrm{NaCl}(a q)=\mathrm{HCl}(g)+\mathrm{NaNO}_{3}(a q) .
\end{gathered}
$$



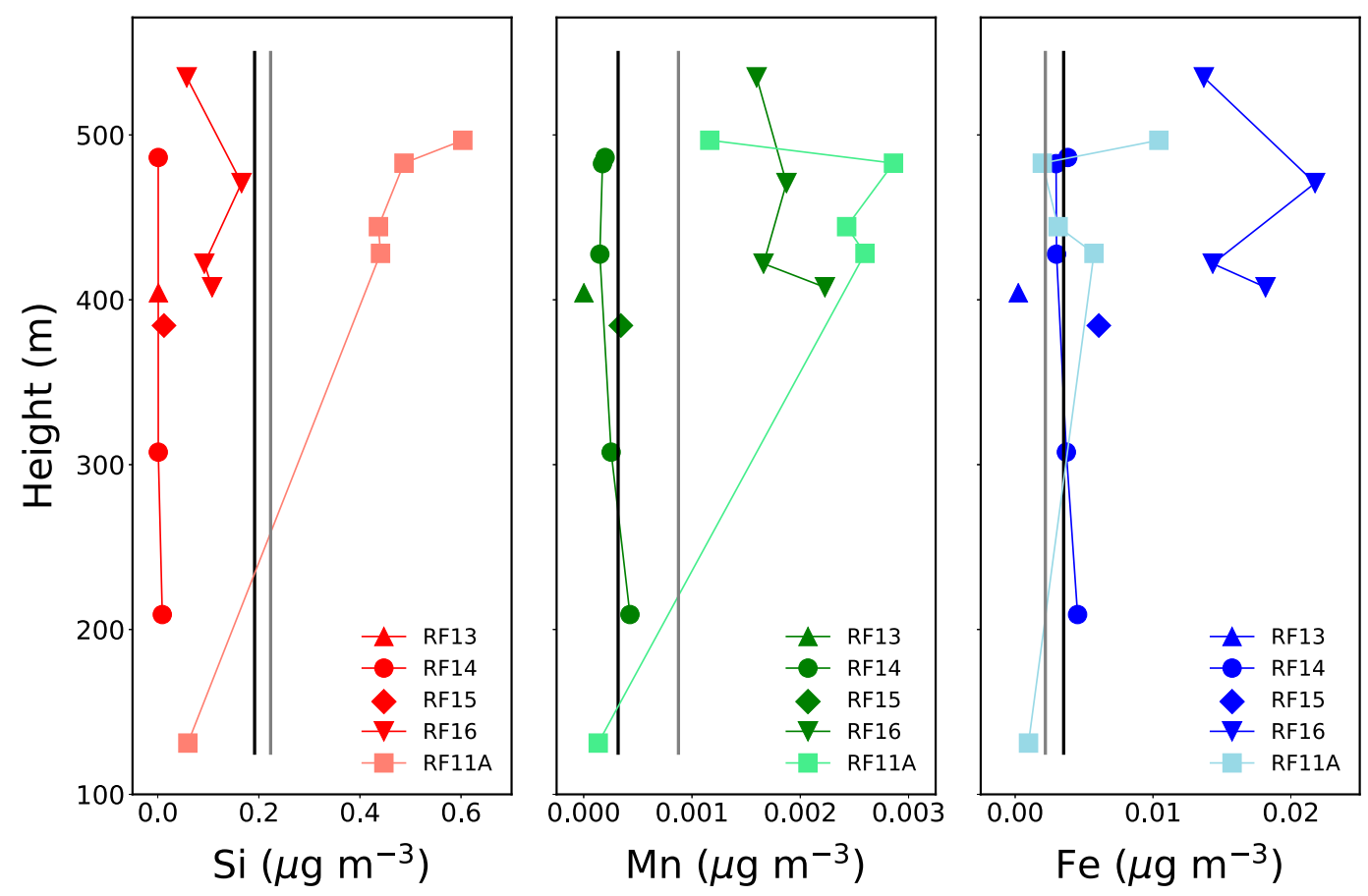

FIG. 9. Vertical profiles of cloud water samples: (left) silicon ( $\mathrm{Si})$, (center) manganese (Mn), and (right) iron (Fe) ion concentrations $\left(\mu \mathrm{g} \mathrm{m}^{-3}\right)$ for E-PEACE CTD day -1 to day +2 (RF13-RF16, respectively) in addition to BOAS CTD day +1 (RF11A). The black and gray vertical lines indicate the E-PEACE and BOAS campaign mean concentrations, respectively.

The apparent reduction in chloride is confirmed through a decrease in the $\mathrm{Cl}: \mathrm{Na}$ ratio $(\sim 1.8$ for natural seawater $)$ over time during the E-PEACE CTD case (not shown). The mean ratios for RF13-RF16 are 2.1,1.9, 1.4, and 1.4, respectively. Therefore, it does appear as though chloride depletion occurs toward the end of the CTD event as higher concentrations of NSS sulfate and nitrate are observed. The Cl:Na ratios from RF11A during BOAS are generally $\geq 1.8$. While it does not appear as though significant chloride depletion is present in the BOAS case, cloud water samples from only one day are available. We note that previous studies using sizeresolved aerosol measurements in the same sampling region find that organic and inorganic acids can also significantly deplete chloride (e.g., Maudlin et al. 2015; Braun et al. 2017).

\section{WRF Model evaluation}

Meteorological grids from NAM and NARR, backward trajectories from HYSPLIT, and chemistry observations from aircraft indicate that the anomalous large-scale meteorological conditions responsible for CTD initiation may also be responsible for the influence of shipping and continental aerosol sources on the marine cloud deck. We now investigate the ability of the WRF Model to represent the MBL dynamics and thermodynamics, in addition to the CTD cloud characteristics.

\section{a. Aircraft observations}

In situ measurements from an airborne platform provide a unique dataset that may be used to evaluate model performance. For each of the three cases, we evaluate the model on the following day: 24 June (day +2; DMIMS), 28 July (day +1 ; RF15 from E-PEACE), and 17 July (day +1 ; RF11A from BOAS). These days are chosen for two reasons: 1) data availability and 2) the cloud field extents are similar on these days (cf. Fig. 5).

We begin by qualitatively comparing aircraft measurements to WRF for DMIMS (Fig. 10). A north-south vertical sawtooth flight track by the UWKA from $\sim 1655-1735$ UTC 24 July 2006 is shown in Fig. 10a. Observations reveal a strong, northerly coastal jet (CJ) atop the clear, warm, and shallow MBL toward the north. At $\sim 75-\mathrm{km}$ distance, the MBL begins to deepen. The UWKA first measures the CTD cloud deck around $100-\mathrm{km}$ distance; however, the clouds may actually be too shallow for the aircraft to sense farther north. The wind shift appears to coincide with the cloud deck, which extends to the top of the strongly capped MBL 

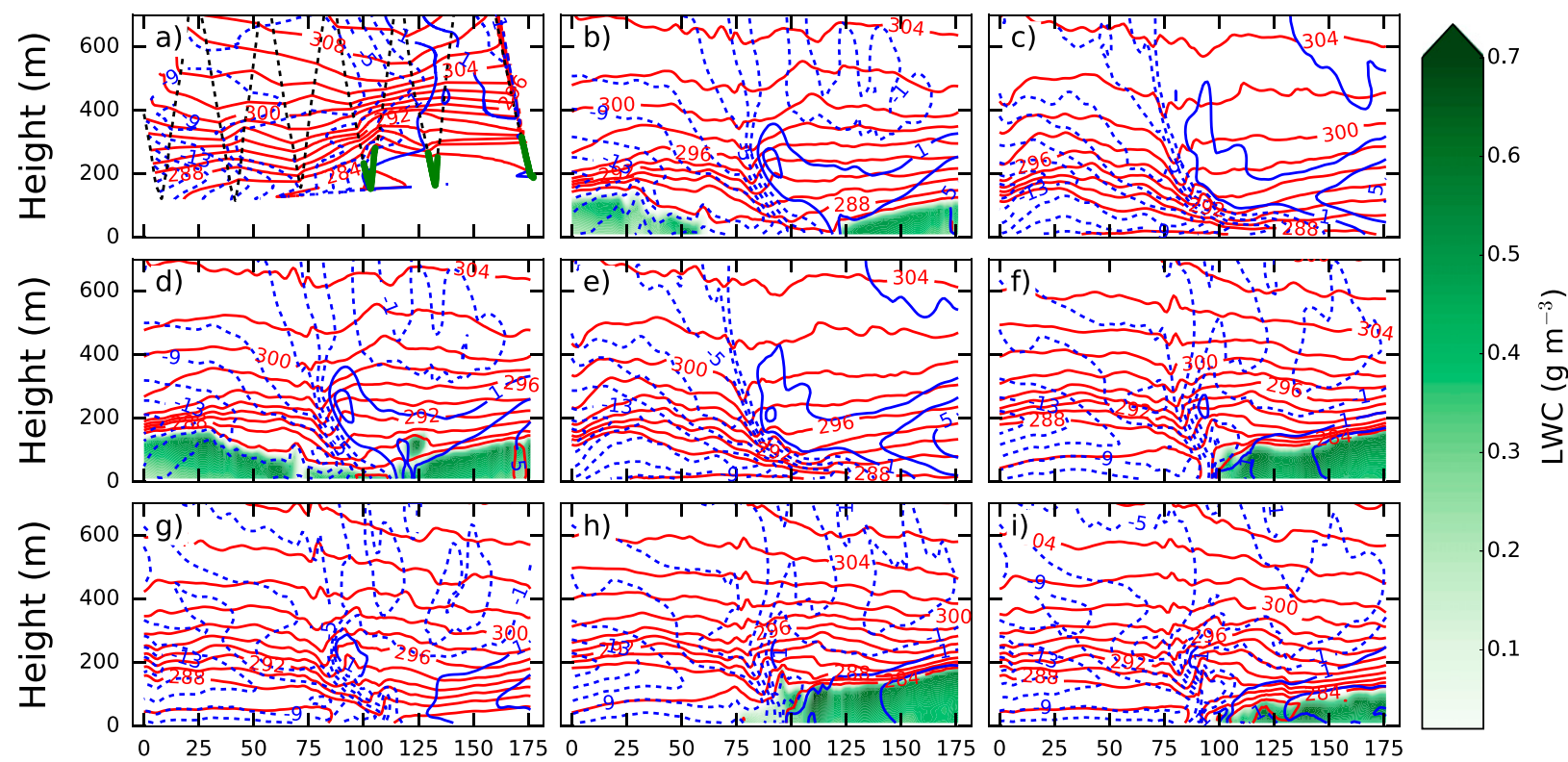

$\mathrm{N}$ Distance $(\mathrm{km}) \mathrm{S}$

$\mathrm{N}$ Distance $(\mathrm{km}) \mathrm{S}$

$\mathrm{N}$ Distance $(\mathrm{km}) \mathrm{S}$

FIG. 10. Vertical sawtooth (ST) flight track during the DMIMS CTD from $\sim 1655$ to 1735 UTC 24 Jul 2006. Potential temperature (solid red lines contoured every $2 \mathrm{~K}$ ), $v$ component of the wind (blue lines contoured every $2 \mathrm{~m} \mathrm{~s}^{-1}$ beginning at $\pm 1 \mathrm{~m} \mathrm{~s}^{-1}$; solid (dashed) lines indicate positive (negative) values), and cloud liquid water content (LWC; color contoured with color bar; $\mathrm{g} \mathrm{m}^{-3}$ ) are plotted (a) for UWKA observations, and for WRF output from various configurations: (b) NARR_M_Y, (c) NARR_M_M, (d) NARR_T_Y, (e) NARR_T_M, (f) NAM_M_Y, (g) NAM_M_M, (h) NAM_T_Y, and (i) NAM_T_M. The LWC contouring in (a) represents regions where the UWKA observed cloud (LWC $>0.02 \mathrm{~g} \mathrm{~m}^{-3}$ ) rather than actual LWC values. The UWKA flight track is also shown in (a). UWKA data are interpolated linearly. In all panels, north (south) is to the left (right) as indicated by the markers "N" ("S") below (g)-(i) (cf. Fig. 1).

( 250-300 m). Although all WRF simulations capture the CJ intensity and location, only the simulations using the YSU PBL scheme (Figs. 10b,d,f,h), in addition to the simulation using NAM forcing, Thompson microphysics, and MYJ PBL (Fig. 10i), reproduce realistic CTD cloud decks. However, the YSU simulations with NARR forcing (Figs. 10b,d) erroneously generate MBL clouds toward the north. For this particular case, the ICs from the driving model likely play an important role (see the appendix). Few differences exist between the microphysics schemes when using NAM forcing. The strength of the capping MBL is also closer to observations in the simulations using NAM forcing. Therefore, the most accurate simulations appear to be those using NAM forcing, YSU PBL, and either Morrison or Thompson microphysics (Figs. 10f,h).

The horizontal variability in winds and cloud LWC during an E-PEACE flight leg during 1925-2000 UTC is examined and compared with the various WRF simulations (Fig. 11). Similar to Fig. 10, the simulations using the MYJ PBL scheme do not produce a realistic cloud field. The simulations with NAM forcing and YSU PBL (Figs. 11f,h) appear to capture the observed LWC values at this particular level $(\sim 305 \mathrm{~m})$, while the simulations with NARR forcing and YSU PBL overestimate LWC. Additionally, the modeled wind field using NAM forcing seems to be more accurate than that using NARR forcing. Sensitivity simulations show that the LBCs may influence the modeled cloud and wind characteristics more than the ICs (see the appendix). In general, the E-PEACE simulations using NAM forcing, YSU PBL, and either Morrison or Thompson microphysics (Figs. 11f,h) produce the most accurate results.

Because flight plans during DMIMS and E-PEACE were conducted on constant pressure or altitude surfaces, we compare the aircraft observations and WRF output quantitatively using histograms of wind speed, wind direction, potential temperature $\theta$, and cloud LWC (Figs. 12, 13). Four DMIMS isobaric flight legs sampled both inside and outside the CTD cloud deck; thus, the histogram shows peaks in both relatively weak $\left(<4 \mathrm{~m} \mathrm{~s}^{-1}\right.$; inside the CTD) and relatively strong $(\sim 8$ and $16 \mathrm{~m} \mathrm{~s}^{-1}$; outside the CTD) wind speed (Fig. 12). Peaks in wind direction near $25^{\circ}$ and $100^{\circ}-200^{\circ}$ correspond to these strong and weak wind regions, respectively. In the E-PEACE case, the measured wind speed and wind direction show a single peak near $4 \mathrm{~m} \mathrm{~s}^{-1}$ and $180^{\circ}$, respectively, because the Twin Otter was mostly inside the CTD for the duration of the 


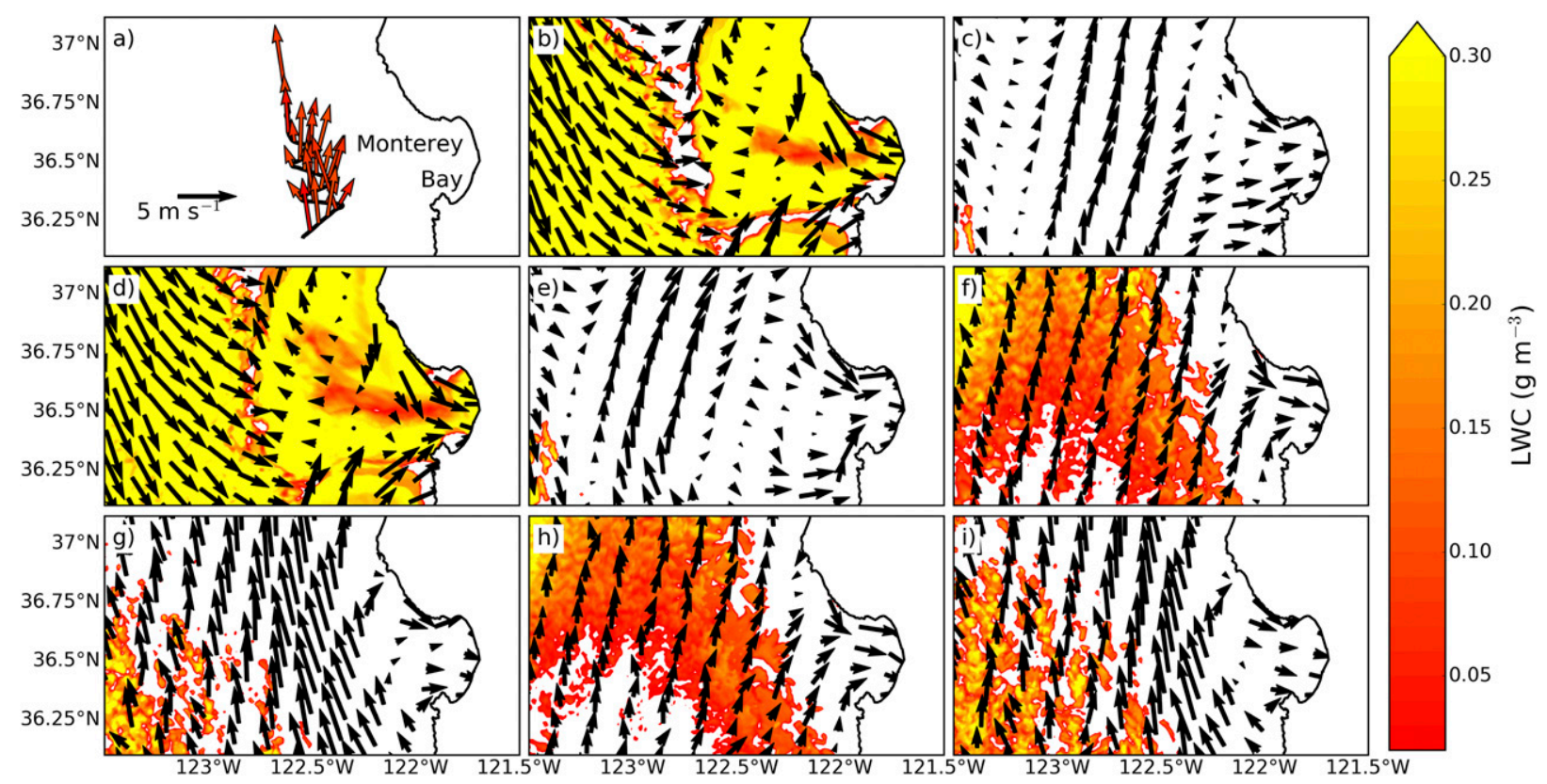

FIG. 11. Flight legs (FL) during the E-PEACE CTD from 1925 to 2000 UTC 28 Jul 2011 (RF15). (a) The flight track (solid black line; mean altitude of $\sim 305 \mathrm{~m} \mathrm{MSL}$ ), the observed wind field [color coded (see color bar) by the observed cloud liquid water content (LWC); $\mathrm{g} \mathrm{m}^{-3}$ ], a reference wind vector $\left(\mathrm{m} \mathrm{s}^{-1}\right)$, and the location of Monterey Bay for geographical reference. Observed LWC values range from about 0.02 to $0.11 \mathrm{~g} \mathrm{~m}^{-3}$. (b)-(i) The modeled wind vector and LWC fields. The various configurations are as follows: (b) NARR_M_Y, (c) NARR_M_M, (d) NARR_T_Y, (e) NARR_T_M, (f) NAM_M_Y, (g) NAM_M_M, (h) NAM_T_Y, and (i) NAM_T_M.

three flight legs (Fig. 13). Temperature within the cloud-topped MBL is relatively low, as $\theta$ values range from about $283-287 \mathrm{~K}$ in DMIMS and $286-288 \mathrm{~K}$ in E-PEACE. Finally, LWCs within the CTD cloud deck remain below $\sim 0.50 \mathrm{~g} \mathrm{~m}^{-3}$ and the distribution for DMIMS (E-PEACE) has a clear peak around $0.3(0.1) \mathrm{g} \mathrm{m}^{-3}$.

Overall, WRF captures the salient meteorological features. Most of the simulations do show a double peak in wind speed for DMIMS (with the exception of the simulations using NARR forcing and YSU PBL); however, they underestimate (overestimate) the frequency of weak (strong) wind speed. This suggests that the model is not representing properly the location and extent of the CJ and CTD features. The wind direction histogram supports this hypothesis because southerly and easterly (northerly) flow frequency is generally underestimated (overestimated). In the E-PEACE case, wind speed is underestimated within the CTD for all simulations except for the simulations with NAM forcing and MYJ PBL scheme. All of the simulations with NAM forcing reproduce the southerly wind direction peak, while those with NARR forcing (with the exception of the Morrison microphysics/MYJ PBL simulation) show a westerly peak, which suggests that there may be an issue inherent to the reanalysis. We attribute this issue to the NARR LBCs because a simulation using NAM ICs and NARR LBCs is not able to resolve the error (see the appendix). One potential source of error may stem from the representation of the terrain and coastline using NARR because it has coarser horizontal resolution than NAM. Moreover, we find that the wind field is sensitive to the microphysics scheme (cf. Fig. 13, top-left and top-right panels). For both CTD events, $\theta$ is overestimated by most simulations. The most plausible explanation is that either 1) the MBL is too shallow in WRF and therefore the comparison altitude is in the inversion layer or 2) clouds are absent in WRF and therefore less incoming shortwave radiation is reflected. All WRF simulations with YSU PBL physics and one simulation with MYJ PBL physics (NAM forcing and Thompson microphysics) produce reasonable cloud LWC values in DMIMS, ${ }^{6}$ although LWC is overestimated slightly in the NARR forcing simulations with YSU PBL physics. For the E-PEACE event, the NAM forcing/YSU PBL simulations produce the most reasonable LWC values, and, similar to DMIMS, the NARR forcing/YSU PBL simulations overestimate LWC.

\footnotetext{
${ }^{6}$ Note that the lack of data lines in the LWC panels in Fig. 12 is because all of the simulations using MYJ PBL generate very little, if any, cloud and therefore represent an excessively warm MBL.
} 

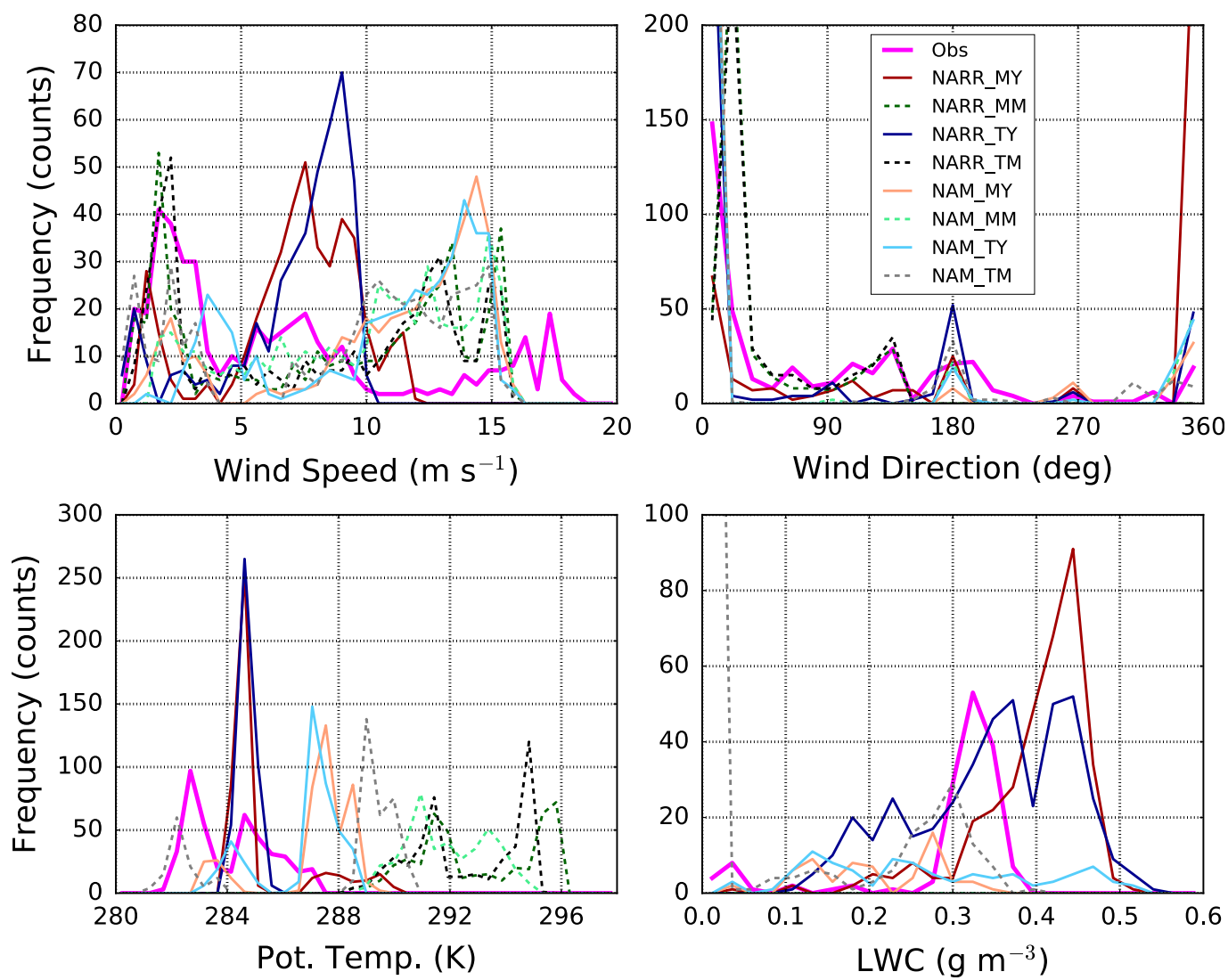

FIG. 12. Histograms (frequency counts) of (top left) wind speed $\left(\mathrm{m} \mathrm{s}^{-1}\right.$; binned every $\left.0.5 \mathrm{~m} \mathrm{~s}^{-1}\right)$, (top right) wind direction $\left({ }^{\circ}\right.$; binned every $\left.15^{\circ}\right)$, (bottom left) potential temperature $\theta(\mathrm{K}$; binned every $0.5 \mathrm{~K})$, and (bottom right) cloud liquid water content (LWC; $\mathrm{g} \mathrm{m}^{-3}$; binned every $0.025 \mathrm{~g} \mathrm{~m}^{-3}$ ) from the DMIMS isobaric (IB) flights during $\sim 1820-1840, \sim 1840-1900, \sim 1900-1915$, and 1915-1940 UTC 24 Jun 2006. All of these IB legs were flown at about $995 \mathrm{hPa}$, which corresponds to an altitude of about 170-175 m MSL. A legend is shown for reference. Solid (dashed) lines represent simulations with YSU (MYJ) PBL.

Spiral profiles from RF11A during BOAS provide an insightful view of the lower atmospheric structure (Figs. 14, 15). Measurements of $\theta, q_{v}$, and cloud LWC are plotted in Fig. 14. The MBL depth varies between about 300 and $500 \mathrm{~m}$ MSL, and the depth decreases northward. Values of $\theta$ and $q_{v}$ in the MBL range from about 286 to $289 \mathrm{~K}$ and from 9 to $10 \mathrm{~g} \mathrm{~kg}^{-1}$, respectively. The MBL $\theta$ is highest (lowest), and consequently $q_{v}$ is highest (lowest), in $\mathrm{S} 1$ (S3). There is a notable weakening in the inversion strength toward the north, as only the S1 $\theta$ and $q_{v}$ traces display a sharp transition between the MBL and free troposphere. Profiles indicate that the highest LWCs $\left(>0.6 \mathrm{~g} \mathrm{~m}^{-3}\right)$ are seen in S1, where the MBL capping is strongest. Maximum LWC values in S2 and S3 are $\sim 0.35 \mathrm{~g} \mathrm{~m}^{-3}$. Upon calculating $H$ and cloud LWP for $\mathrm{S} 1, \mathrm{~S} 2$, and S3 (Table 2), we find that $H$ in the CTD is approximately the same ( 328.8 vs $316.7 \mathrm{~m}$ ) for $\mathrm{S} 1$ and S2; however, LWP is much greater for S1 (114.0 vs $\left.46.2 \mathrm{~g} \mathrm{~m}^{-2}\right)$. In S3, $H$ is much less $(192.9 \mathrm{~m})$ than both
S1 and S2, although LWP is nearly the same as S2 $\left(41.1 \mathrm{~g} \mathrm{~m}^{-2}\right)$.

Using in situ measurements, we calculate the adiabatic liquid water lapse rate $\Gamma_{\mathrm{LWC}_{a d}}$ following the relation from Albrecht et al. (1990):

$$
\Gamma_{\mathrm{LWC}_{\mathrm{ad}}}=\frac{P_{\mathrm{cb}}-e_{s}\left(T_{\mathrm{cb}}\right)}{R_{d} T_{\mathrm{cb}}} \Gamma_{l}\left(P_{\mathrm{cb}}, T_{\mathrm{cb}}\right),
$$

where $P_{\mathrm{cb}}$ and $T_{\mathrm{cb}}$ are the pressure and temperature at cloud base, respectively, $e_{s}\left(T_{\mathrm{cb}}\right)$ is the saturation vapor pressure at cloud base, $R_{d}$ is the gas constant for dry air, and $\Gamma_{l}\left(P_{\mathrm{cb}}, T_{\mathrm{cb}}\right)$ is the lapse rate of liquid water mixing ratio. The adiabatic cloud liquid water path $\left(\mathrm{LWP}_{\mathrm{ad}}\right)$ is then

$$
\mathrm{LWP}_{\mathrm{ad}}=\frac{1}{2} \Gamma_{\mathrm{LWC}_{\mathrm{ad}}}\left(z_{\mathrm{ct}}-z_{\mathrm{cb}}\right)^{2},
$$

where $z_{\mathrm{ct}}$ and $z_{\mathrm{cb}}$ are cloud-top height and cloud-base height, respectively. The measured LWP is equal to the 

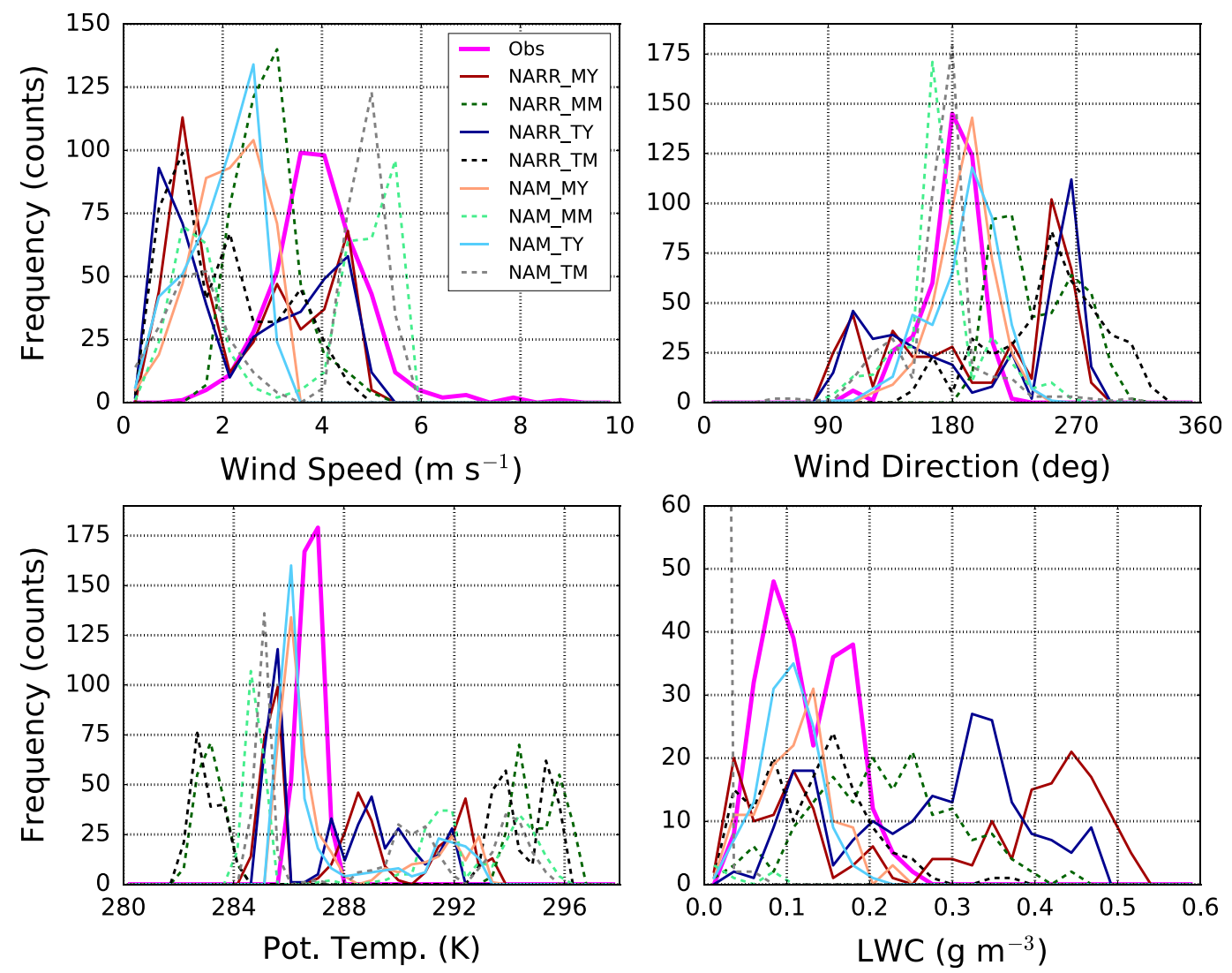

FIG. 13. As in Fig. 12, but for the E-PEACE flight legs (FL) during $\sim 1825-1920, \sim 1925-2000$, and 2005-2040 UTC 28 Jul 2011 (RF15). These legs were flown at about 25, 305, and $355 \mathrm{~m}$ MSL, respectively.

LWP $_{a d}$ if the cloudy parcel moves adiabatically ${ }^{7}$ and does not exchange heat with its environment. Therefore, we may use the ratio of LWP to LWP $\mathrm{Fd}_{\mathrm{ad}}$ as an indicator for the amount of mixing between the cloud parcel and its surroundings (e.g., Pawlowska and Brenguier 2003). Of course, clouds in the real world are not purely adiabatic because mixing occurs between the cloud parcel and its environment. During the BOAS CTD, the clouds sampled in S1, S2, and S3 are $88.5 \%, 38.6 \%$, and $93.4 \%$ of their $\mathrm{LWP}_{\mathrm{ad}}$ values, respectively (Table 2). The ratios for $\mathrm{S} 1$ and $\mathrm{S} 3$ are consistent with $\mathrm{LWC}$ to $\mathrm{LWC}_{\mathrm{ad}}$ values from other marine stratocumulus cases; however, the ratio for S2 resembles those for shallow cumuli clouds (e.g., Brenguier et al. 2011). We hypothesize that the marked departure from adiabaticity may be due to a localized enhancement of entrainment. Also, the vertical profiles of $\theta$ and $q_{v}$ in S2 (cf. Fig. 14) show evidence of vertical

\footnotetext{
${ }^{7}$ In a saturated parcel that moves adiabatically, $N_{c}$ is constant and LWC increases linearly with height (e.g., Brenguier et al. 2000; Wood and Hartmann 2006).
}

mixing between the MBL and free troposphere (e.g., Rahn et al. 2016).

Figure 15 shows observations of horizontal wind speed, wind direction, and vertical wind speed. There is a complicated vertical structure of wind speed in all three soundings as wind speed generally decreases toward the north. In S1 and S2, the wind has a southerly component through the entire sounding, and the direction is mostly alongshore (from the southeast). A strong contrast between the MBL and free troposphere is apparent in S2: a wind speed maximum of $\sim 8 \mathrm{~m} \mathrm{~s}^{-1}$ is present at the top of the MBL and the wind direction shifts from southerly within the MBL to southeasterly above the MBL. This coherent vertical structure is not seen in S1. Toward the north at S3, the aircraft is just south of Cape Mendocino (cf. Fig. 1). The CTD layer here is shallower than that in S1 and S2, and the wind direction above the MBL shows a complicated structure in which the flow is northerly between about 400 and $800 \mathrm{~m}$ before returning to southerly at $800 \mathrm{~m}$. Each of the three spiral profiles show a turbulent MBL structure with vertical velocities lying between approximately -0.6 and $+0.6 \mathrm{~m} \mathrm{~s}^{-1}$. 

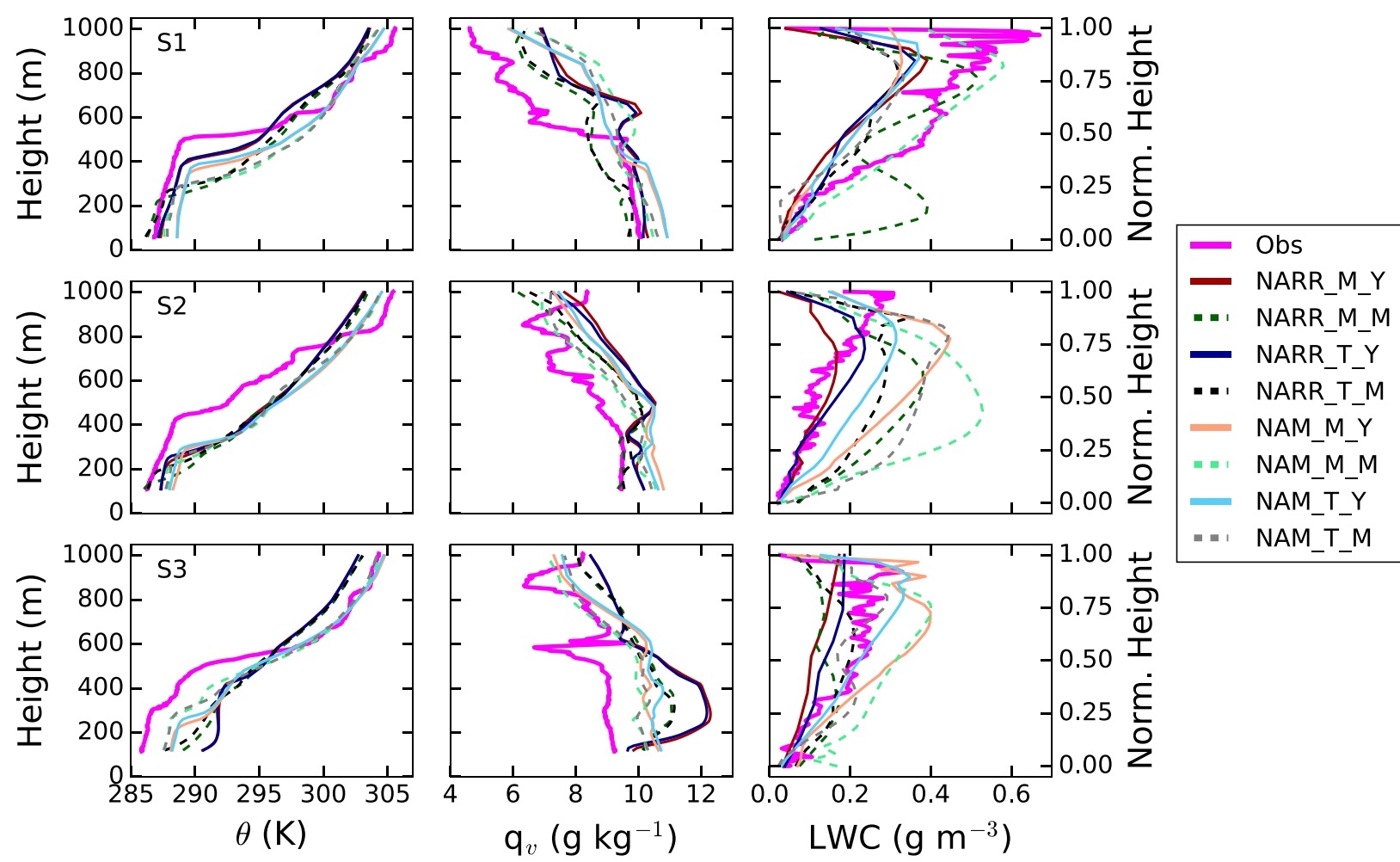

FIG. 14. Vertical spiral profiles from the BOAS CTD event during (top) 1741-1750 (S1), (middle) 1811-1819 (S2), and (bottom) $\sim 1838-1845$ (S3) UTC 17 Jul 2015 (RF11A). For each profile, (left) potential temperature $\theta$ (K), (middle) water vapor mixing ratio $q_{v}$ $\left(\mathrm{g} \mathrm{kg}^{-1}\right.$ ), and (right) cloud liquid water content (LWC; $\mathrm{g} \mathrm{m}^{-3}$ are shown. $\theta$ and $q_{v}$ are plotted throughout the depth of the vertical profile, while LWC is plotted against normalized height for clarity. The normalized height for each LWC profile is determined by cloud-base height (a normalized value of " 0 ") and cloud-top height (a normalized value of " 1 "). A legend is shown for reference. Solid (dashed) lines represent simulations with YSU (MYJ) PBL. Root-mean-square error statistics are listed in Table 3.

When we compare output from the various WRF configurations to the observations, our results are similar to previous studies (e.g., Rahn and Garreaud 2010; Andrejczuk et al. 2012; Chen et al. 2015). Most notably, the MBL top is too low in WRF for all of the BOAS soundings. Even with a very fine vertical grid spacing $(\sim 10 \mathrm{~m}$ in the lowest $500 \mathrm{~m})$, the model still cannot reproduce the sharp inversion atop the MBL in S1. Broadly speaking, the $\theta$ and $q_{v}$ profiles suggest that WRF is too warm and moist. The cloud LWC profiles show an underestimation in values in $\mathrm{S} 1$ for all simulations with the exception of those using Morrison microphysics and MYJ PBL. Moreover, nearly all simulations overpredict LWCs for S2, and for S3, the simulations forced with NARR (NAM) underpredict (overpredict) LWCs. Wind speed is generally underpredicted for all soundings, and the model profiles do not display the complicated vertical structure. Wind direction is well-represented in the WRF simulations; the aforementioned complex structures in S2 and S3 are captured. Vertical velocity is grossly underestimated in WRF; however, this is not surprising because the aircraft has much greater resolution than the model. Additionally, because we average multiple model soundings, we expect the vertical velocity to be near zero. Thus, we plot 5 times the standard deviation of $w$, which, as expected, yields a larger range within the MBL compared to the free troposphere.

A root-mean-square error (RMSE) analysis for $\theta$, $u$ component of the wind, $v$ component of the wind, $w$ component of the wind, and $q_{v}$ is compiled in Table 3 . The RMSEs are fairly large for $\theta$ because the MBL is too warm in S1 and too shallow in all three soundings. In general, the combination of NAM forcing, Thompson microphysics, and YSU PBL is the best at predicting the thermodynamics. Our results suggest that the simulations with NAM forcing represent the $u$ and $v$ components of the wind, in addition to $q_{v}$, better than those with NARR forcing. The forecast error in the horizontal wind is similar between the microphysics schemes and slightly different between the PBL schemes; however, the MYJ PBL scheme seems to predict the $q_{v}$ field better than the YSU PBL scheme, perhaps due to the lack of cloud in the MYJ simulations. 

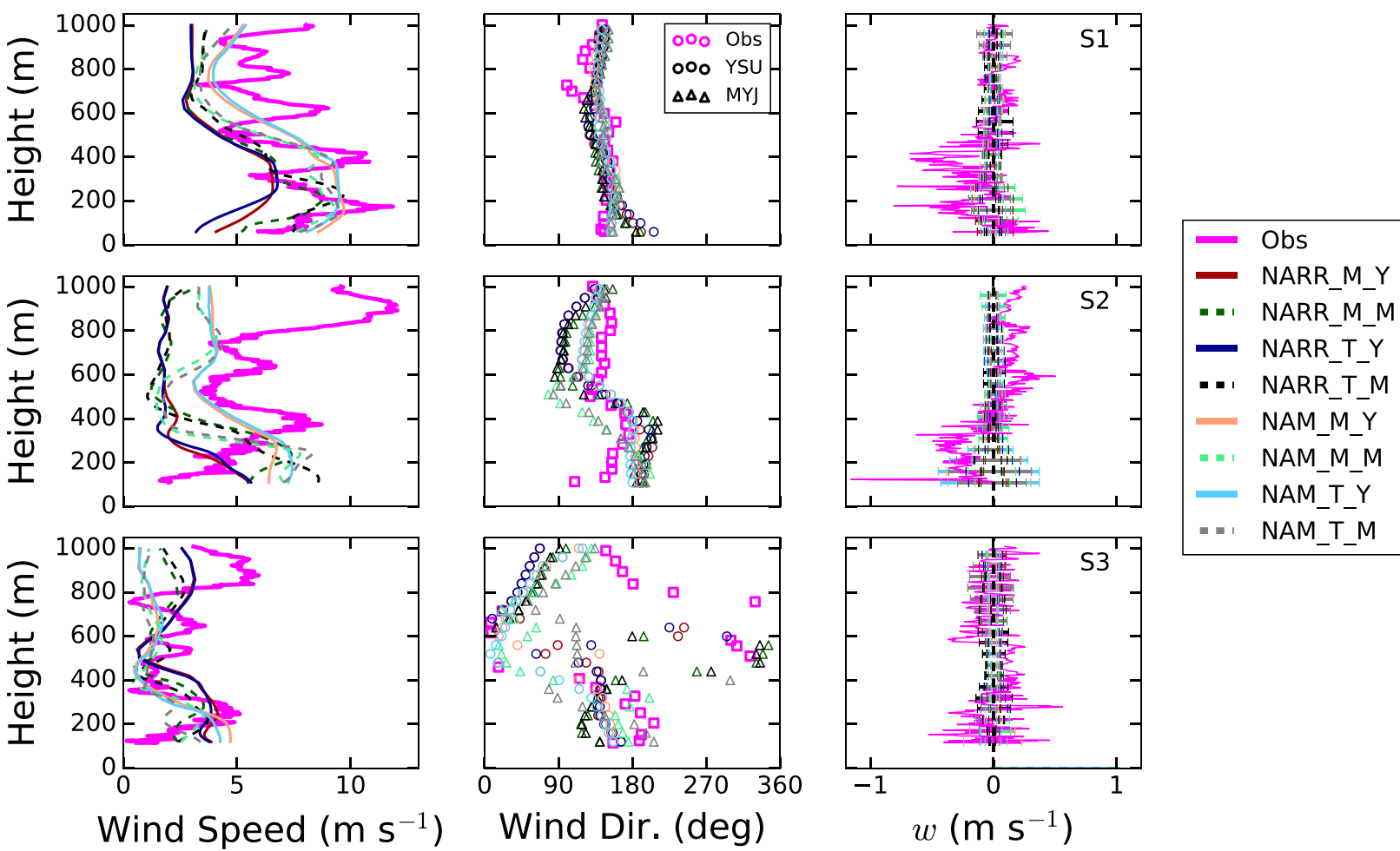

FIG. 15. As in Fig. 14, but for (left) wind speed $\left(\mathrm{m} \mathrm{s}^{-1}\right)$, (center) wind direction $\left(^{\circ}\right)$, and (right) vertical velocity $w\left(\mathrm{~m} \mathrm{~s}^{-1}\right)$. The horizontal bars in the right column represent 5 times the standard deviation of $w$. Root-mean-square error statistics are listed in Table 3.

Moreover, this analysis confirms the gross underestimation of $w$ across all simulations.

In general, because WRF underestimates MBL depth, it also underestimates $H$. This is especially true in S1 and S2, where all simulations produce a CTD cloud layer that is typically $20 \%-40 \%$, and up to $\sim 60 \%$, too shallow (Table 2). For S3, the model simulations forced with NARR (NAM) underestimate (overestimate) $H$. As expected, each of the simulations using NARR forcing underpredicts cloud LWP. A surprising result, however, is seen in the LWP predictions for some of the WRF simulations with NAM forcing. Specifically, for S2, all model combinations using NAM forcing create a cloud layer that is too shallow and a LWP that is much too high due to a gross overestimation of LWC. Sensitivity studies for this case suggest that the LBCs, rather than the ICs, strongly influence these results (not shown).

Overall, NAM forcing and YSU PBL perform best for predictions of $H$, while Morrison and Thompson microphysics predict $H$ with similar accuracy. For predictions of LWP, NARR forcing performs considerably better than NAM forcing. In some instances, the PBL parameterization affects predictions of $H$ and $L W P$ as much as or more than either the driving model or the microphysics scheme. Previous studies also show that the parameterization method for turbulence may be more important than that for microphysics when predicting LWP (e.g., Zhu et al. 2005; Wyant et al. 2007). Our results suggest that properly representing internal CTD dynamics, which drive the MBL cloud microphysics, is critical to accurately predicting LWP. Using $\mathrm{S} 1, \mathrm{~S} 2$, and S3, we are not able to state confidently which microphysics and PBL schemes perform best for LWP because the various combinations produce inconsistent results. For instance, MYJ PBL physics most accurately predict LWP for the simulations with NARR forcing, but least accurately predict LWP for the simulations with NAM forcing.

\section{b. MODIS retrievals}

While the in situ aircraft measurements provide important local information, MODIS provides vertically integrated information across a large region and thus supplies another variable to evaluate the model. Cloud LWP values are now compared between MODIS and WRF (Figs. 16-18). For each of the three cases, we select the same day for comparison as in the previous section: 24 June (day +2; DMIMS), 28 July (day +1 ; RF15 from E-PEACE), and 17 July (day +1 ; RF11A from BOAS). The panel plan views display LWP from the MODIS retrieval in addition to WRF output from each of the 
TABLE 2. Summary of cloud depth $H$ and cloud liquid water path (LWP) statistics for BOAS spiral profiles (S1, S2, and S3) vs model output. For the observations using the PVM-100A probe, the actual (adiabatic) LWP values, in addition to the actual LWP to adiabatic LWP ratios, are shown for each spiral profile. We note that for S3, the spiral profile begins at $\sim 115 \mathrm{~m}$ MSL and in cloud (LWC $\approx$ $\left.0.04 \mathrm{~g} \mathrm{~m}^{-3}\right)$. Even if cloud base extends to the ocean surface, additional contribution to LWP would likely be minimal $(\leqslant 5 \%$ of our calculated LWP value), and LWP errors would be slightly worse (better) for those simulations using NARR (NAM) LBCs.

\begin{tabular}{|c|c|c|c|c|c|}
\hline Data or simulation & Sounding & $H(\mathrm{~m})$ & $H$ (\% error) & $\mathrm{LWP}\left(\mathrm{g} \mathrm{m}^{-2}\right),\left(\mathrm{LWP} / \mathrm{LWP}_{\mathrm{ad}}\right)$ & LWP (\% error) \\
\hline \multirow[t]{3}{*}{ PVM-100A Probe } & $\mathrm{S} 1$ & 328.8 & - & 114.0 (128.8), 0.885 & - \\
\hline & $\mathrm{S} 2$ & 316.7 & - & 46.2 (119.6), 0.386 & - \\
\hline & $\mathrm{S} 3$ & 192.9 & - & $41.1(44.0), 0.934$ & - \\
\hline \multirow[t]{4}{*}{ NARR_M_Y } & $\mathrm{S} 1$ & 292.6 & -11.0 & 63.3 & -44.5 \\
\hline & $\mathrm{S} 2$ & 164.3 & -48.1 & 18.8 & -59.3 \\
\hline & S3 & 93.2 & -51.7 & 10.9 & -73.4 \\
\hline & $\mid$ Mean| & - & 36.9 & - & 59.1 \\
\hline \multirow[t]{4}{*}{ NARR_M_M } & S1 & 240.6 & -26.8 & 94.8 & -16.8 \\
\hline & $\mathrm{S} 2$ & 123.4 & -61.0 & 36.9 & -20.0 \\
\hline & S3 & 53.9 & -72.1 & 7.1 & -82.7 \\
\hline & $\mid$ Mean $\mid$ & - & $\mathbf{5 3 . 3}$ & - & 39.8 \\
\hline \multirow[t]{4}{*}{ NARR_T_Y } & S1 & 284.8 & -13.4 & 64.8 & -43.2 \\
\hline & $\mathrm{S} 2$ & 160.7 & -49.3 & 24.5 & -46.9 \\
\hline & S3 & 109.3 & -43.3 & 15.9 & -61.2 \\
\hline & $\mid$ Mean $\mid$ & - & 35.3 & - & 50.4 \\
\hline \multirow[t]{4}{*}{ NARR_T_M } & S1 & 214.6 & -34.7 & 51.3 & -55.0 \\
\hline & $\mathrm{S} 2$ & 193.8 & -38.8 & 47.5 & +3.0 \\
\hline & S3 & 100.4 & -47.9 & 18.1 & -56.0 \\
\hline & $\mid$ Mean $\mid$ & - & 40.5 & - & 38.0 \\
\hline \multirow[t]{4}{*}{ NAM_M_Y } & $\mathrm{S} 1$ & 213.4 & -35.1 & 46.0 & -59.7 \\
\hline & $\mathrm{S} 2$ & 244.7 & -22.7 & 78.7 & +70.3 \\
\hline & S3 & 247.3 & +28.2 & 67.4 & +64.0 \\
\hline & $\mid$ Mean| & - & 28.7 & - & 64.7 \\
\hline \multirow[t]{4}{*}{ NAM_M_M } & $\mathrm{S} 1$ & 211.0 & -35.8 & 87.1 & -23.6 \\
\hline & $\mathrm{S} 2$ & 205.4 & -35.1 & 87.0 & +88.5 \\
\hline & S3 & 267.9 & +38.9 & 83.5 & +103.2 \\
\hline & $\mid$ Mean $\mid$ & - & 36.6 & - & 71.8 \\
\hline \multirow[t]{4}{*}{ NAM_T_Y } & S1 & 238.6 & -27.4 & 56.1 & -50.7 \\
\hline & $\mathrm{S} 2$ & 195.1 & -38.4 & 47.3 & +2.5 \\
\hline & S3 & 239.6 & +24.2 & 59.1 & +43.7 \\
\hline & $\mid$ Mean $\mid$ & - & 30.0 & - & 32.3 \\
\hline \multirow[t]{4}{*}{ NAM_T_M } & $\mathrm{S} 1$ & 227.5 & -30.8 & 51.3 & -55.0 \\
\hline & $\mathrm{S} 2$ & 255.3 & -19.4 & 95.3 & +106.3 \\
\hline & S3 & 276.5 & +43.4 & 59.8 & +45.6 \\
\hline & $\mid$ Mean| & - & 31.2 & - & 69.0 \\
\hline
\end{tabular}

eight sensitivity simulations. The histograms are constrained by the red polygon.

For the DMIMS case, the YSU PBL scheme outperforms the MYJ PBL scheme regardless of the driving model or microphysics scheme (Fig. 16). In the simulations that use the MYJ scheme, only those with Thompson microphysics produce some cloud; however, all simulations with the YSU scheme produce a welldefined cloud deck. These results suggest that, while both the microphysics and PBL parameterizations appear to play a role, a major culprit may be the fundamental difference in vertical mixing methods between the two PBL parameterizations, in addition to the explicit parameterization of entrainment in the YSU scheme. We hypothesize that insufficient vertical motion and/or too much entrainment in the MBL may lead to underestimated humidity values. The NARR forcing, and specifically, the NARR LBCs (not shown), appears to produce too much cloud to the north and west and generally overpredict LWP, whereas the simulations using NAM forcing more accurately produce cloud extent and the location of high LWP. Also, the Morrison scheme produces larger LWP values than the Thompson scheme, which may be attributed to cloud microphysical processes such as autoconversion. The Berry and Reinhardt (1974) parameterization is known to convert 
TABLE 3. Summary of meteorological root-mean-square error statistics for BOAS spiral profiles (S1, S2, and S3) vs model output: potential temperature $\theta, u$ component of the wind $u, v$ component of the wind $v$, vertical velocity $w$, and water vapor mixing ratio $q_{v}$.

\begin{tabular}{|c|c|c|c|c|c|c|}
\hline Simulation & Sounding & $\theta(\mathrm{K})$ & $u\left(\mathrm{~m} \mathrm{~s}^{-1}\right)$ & $v\left(\mathrm{~m} \mathrm{~s}^{-1}\right)$ & $w\left(\mathrm{~m} \mathrm{~s}^{-1}\right)$ & $q_{v}\left(\mathrm{~g} \mathrm{~kg}^{-1}\right)$ \\
\hline \multirow[t]{4}{*}{ NARR_M_Y } & $\mathrm{S} 1$ & 2.08 & 2.49 & 2.45 & 0.20 & 1.75 \\
\hline & $\mathrm{S} 2$ & 3.00 & 2.69 & 4.93 & 0.19 & 1.40 \\
\hline & S3 & 3.52 & 1.92 & 3.33 & 0.15 & 2.20 \\
\hline & Mean & 2.87 & 2.37 & 3.57 & 0.18 & 1.78 \\
\hline \multirow[t]{4}{*}{ NARR_M_M } & $\mathrm{S} 1$ & 3.02 & 2.08 & 2.30 & 0.20 & 1.14 \\
\hline & $\mathrm{S} 2$ & 3.12 & 3.05 & 4.62 & 0.20 & 1.07 \\
\hline & $\mathrm{S} 3$ & 3.21 & 1.79 & 2.77 & 0.14 & 1.61 \\
\hline & Mean & 3.12 & 2.31 & 3.23 & 0.18 & 1.27 \\
\hline \multirow[t]{4}{*}{ NARR_T_Y } & $\mathrm{S} 1$ & 2.00 & 2.64 & 2.59 & 0.20 & 1.66 \\
\hline & $\mathrm{S} 2$ & 3.03 & 2.66 & 5.02 & 0.20 & 1.35 \\
\hline & $\mathrm{S} 3$ & 3.53 & 1.83 & 3.32 & 0.15 & 2.12 \\
\hline & Mean & 2.85 & 2.38 & 3.64 & 0.18 & 1.71 \\
\hline \multirow[t]{4}{*}{ NARR_T_M } & $\mathrm{S} 1$ & 2.87 & 1.96 & 2.25 & 0.20 & 1.23 \\
\hline & $\mathrm{S} 2$ & 3.02 & 2.84 & 5.04 & 0.19 & 1.03 \\
\hline & S3 & 2.98 & 1.96 & 2.80 & 0.14 & 1.57 \\
\hline & Mean & 2.96 & 2.25 & 3.36 & 0.18 & 1.28 \\
\hline \multirow[t]{4}{*}{ NAM_M_Y } & $\mathrm{S} 1$ & 2.81 & 1.50 & 1.67 & 0.19 & 1.63 \\
\hline & $\mathrm{S} 2$ & 3.28 & 1.98 & 3.56 & 0.18 & 1.28 \\
\hline & $\mathrm{S} 3$ & 2.48 & 1.51 & 2.58 & 0.14 & 1.30 \\
\hline & Mean & 2.86 & 1.66 & 2.60 & 0.17 & 1.40 \\
\hline \multirow[t]{4}{*}{ NAM_M_M } & $\mathrm{S} 1$ & 3.59 & 1.86 & 1.63 & 0.20 & 2.02 \\
\hline & $\mathrm{S} 2$ & 3.11 & 2.41 & 4.39 & 0.19 & 0.83 \\
\hline & S3 & 1.92 & 1.24 & 2.24 & 0.14 & 1.05 \\
\hline & Mean & 2.87 & 1.84 & 2.75 & 0.18 & 1.30 \\
\hline \multirow[t]{4}{*}{ NAM_T_Y } & $\mathrm{S} 1$ & 2.67 & 1.52 & 1.52 & 0.19 & 1.67 \\
\hline & $\mathrm{S} 2$ & 3.18 & 1.84 & 3.76 & 0.19 & 1.29 \\
\hline & $\mathrm{S} 3$ & 2.37 & 1.58 & 2.61 & 0.14 & 1.47 \\
\hline & Mean & 2.74 & 1.65 & 2.63 & 0.17 & 1.48 \\
\hline \multirow[t]{4}{*}{ NAM_T_M } & $\mathrm{S} 1$ & 3.52 & 1.83 & 1.65 & 0.19 & 1.82 \\
\hline & $\mathrm{S} 2$ & 3.04 & 2.26 & 4.37 & 0.18 & 0.87 \\
\hline & $\mathrm{S} 3$ & 2.12 & 1.30 & 2.54 & 0.14 & 1.15 \\
\hline & Mean & 2.89 & 1.80 & 2.85 & 0.17 & 1.28 \\
\hline
\end{tabular}

cloud water to rainwater (i.e., generate drizzle) faster than the Khairoutdinov and Kogan (2000) scheme (Lee and Baik 2017), which may lead to smaller LWP values. Visually, it appears as though all of the YSU simulations adequately represent the cloud LWP field on this particular day. The distribution parameters, including mean $\mu$, standard deviation $\sigma$, and skewness $\gamma$, indicate that the model configurations using NARR forcing, YSU PBL, and Morrison/Thompson microphysics perform best for this particular case (Table 4).

In modeling the E-PEACE CTD, NARR forcing generally captures the areal cloud coverage better (Fig. 17). For instance, the simulations forced by NAM indicate clear sky in a region within about 200-300 km of the coastline, stretching from approximately the San Francisco Bay southward. One potential reason for the notable cloud dissipation region using NAM forcing is too weak of an inversion that leads to an overestimation in entrainment. In this same region, MODIS shows cloud LWP values ranging from approximately $25-100 \mathrm{~g} \mathrm{~m}^{-2}$. The MYJ scheme appears to enhance the cloudless area, and this is especially apparent in the NARR forcing simulations. Moreover, the simulations forced by NAM represent more accurately the northern extent of the cloud deck. This is most likely due to the LBCs (not shown). Similar to the DMIMS case, the Thompson scheme produces slightly lower LWPs than the Morrison scheme. Taking a visual approach, and using the frequency distribution as support (Fig. 17), the simulations using NARR forcing, YSU PBL, and Morrison/Thompson microphysics once again replicate best the LWP field. For these two simulations, we suspect that the overestimation of $\sigma$ and $\gamma$ is due to the long right tail of the histograms.

According to the MODIS retrievals for BOAS, the cloud deck adjacent to the coastline is not as continuous 

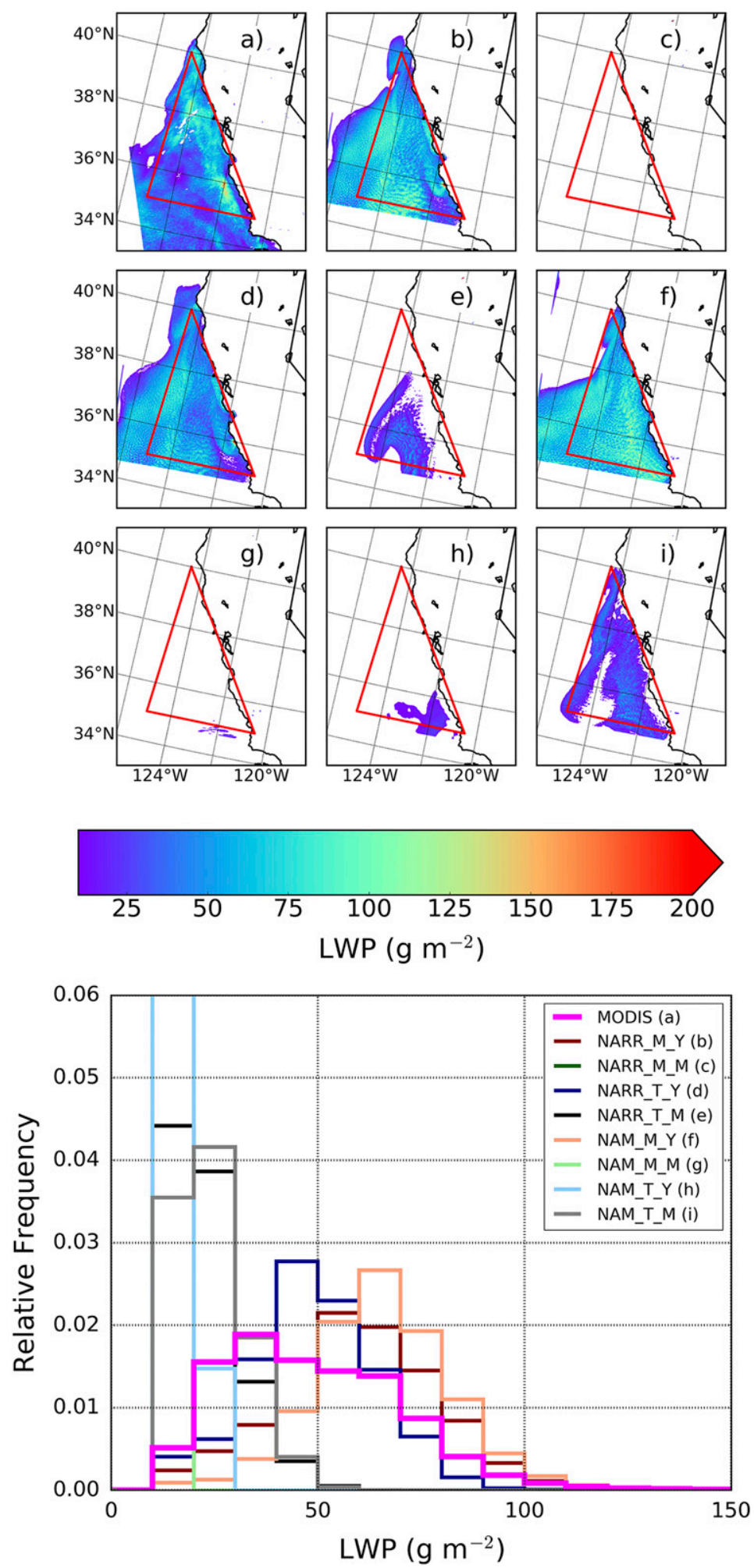

FIG. 16. Plan views of cloud liquid water path (LWP; color contoured with color bar; $\mathrm{g} \mathrm{m}^{-2}$ ) for the DMIMS CTD case as retrieved by (a) MODIS, and modeled by the various WRF configurations: (b) NARR_M_Y, (c) NARR_M_M, (d) NARR_T_Y, (e) NARR_T_M, (f) NAM_M_Y, (g) NAM_M_M, (h) NAM_T Y, and (i) NAM_T_M. Histograms (relative frequency) of the LWP fields (constrained to the red polygon) are also shown. Distribution statistics are listed in Table 4. A legend is shown for reference. 

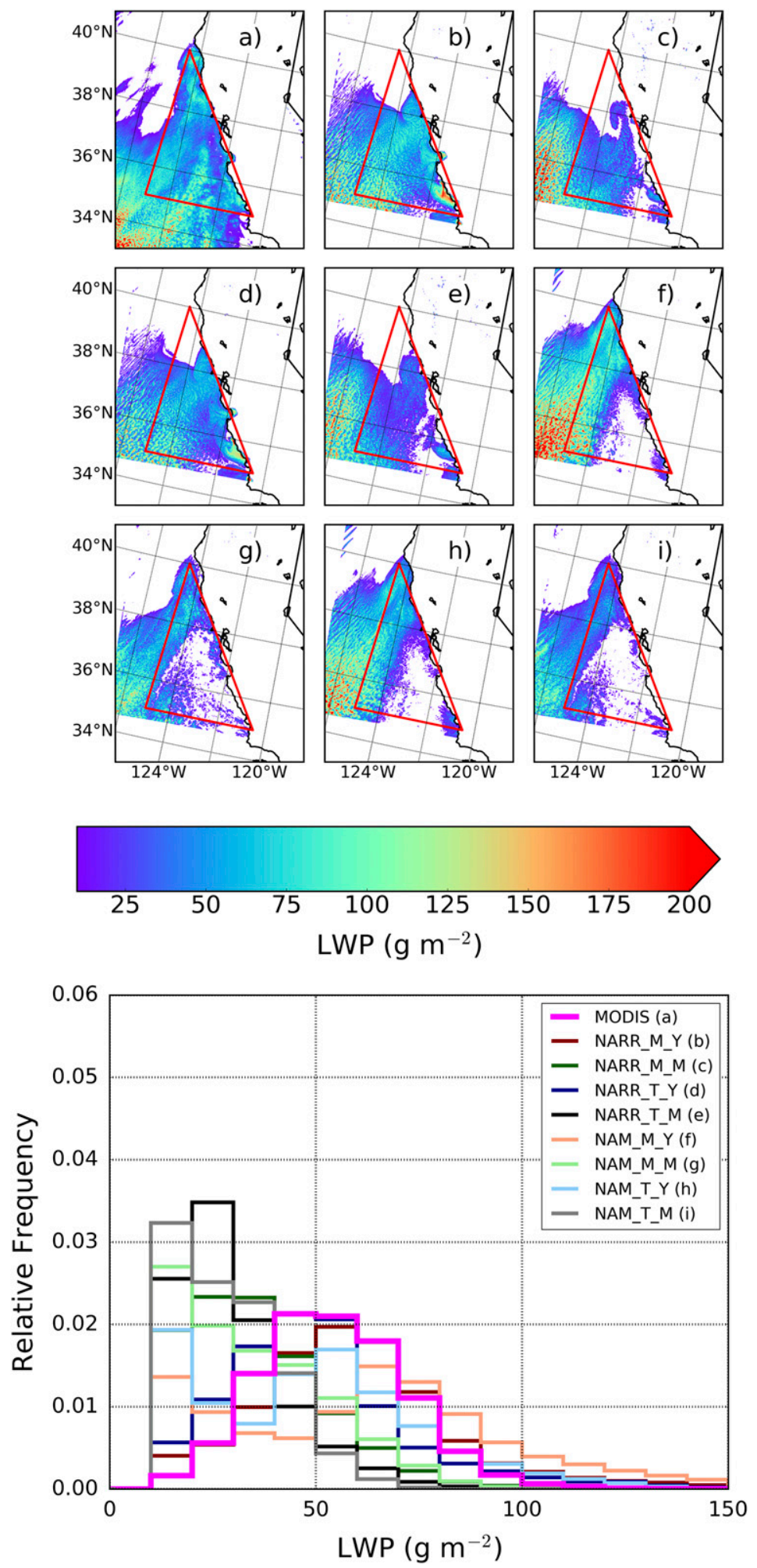

FIG. 17. As in Fig. 16, but for the E-PEACE CTD case. 

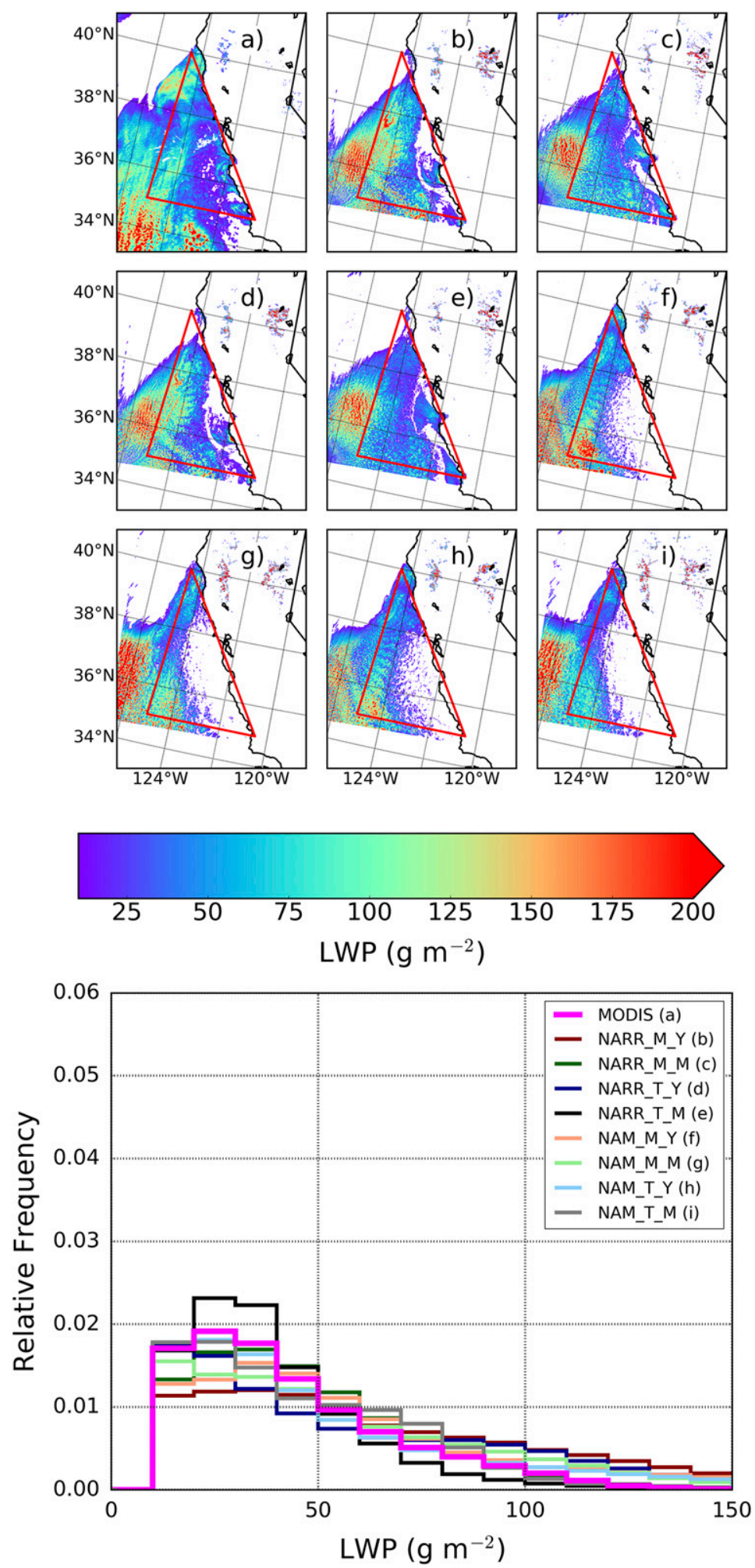

FIG. 18. As in Fig. 16, but for the BOAS CTD case. 
TABLE 4. Summary of cloud liquid water path (LWP) distribution statistics for MODIS vs model output: mean $\mu$ (first moment; $\mathrm{g} \mathrm{m}^{-2}$ ), standard deviation $\sigma$ (second moment; $\mathrm{g} \mathrm{m}^{-2}$ ), and skewness $\gamma$ (third moment; unitless). No statistics are available for the NARR/Morrison/MYJ simulation of the DMIMS case because it does not generate a cloud field.

\begin{tabular}{|c|c|c|c|c|c|c|c|c|c|}
\hline \multirow[b]{2}{*}{ Data or simulation } & \multicolumn{3}{|c|}{ DMIMS } & \multicolumn{3}{|c|}{ E-PEACE } & \multicolumn{3}{|c|}{ BOAS } \\
\hline & $\mu$ & $\sigma$ & $\gamma$ & $\mu$ & $\sigma$ & $\gamma$ & $\mu$ & $\sigma$ & $\gamma$ \\
\hline MODIS & 49.2 & 21.7 & 0.82 & 54.5 & 17.7 & 0.42 & 44.0 & 25.8 & 1.09 \\
\hline NARR_M_Y & 59.4 & 19.9 & 0.62 & 60.5 & 28.4 & 3.20 & 66.4 & 44.5 & 1.77 \\
\hline NARR_M_M & - & - & - & 35.4 & 17.2 & 1.37 & 47.5 & 27.2 & 1.34 \\
\hline NARR_T_Y & 49.2 & 16.3 & 1.06 & 50.7 & 25.1 & 3.51 & 57.3 & 41.1 & 1.93 \\
\hline NARR_T_M & 22.4 & 8.5 & 0.85 & 29.7 & 14.2 & 1.77 & 38.9 & 22.0 & 1.93 \\
\hline NAM_M_Y & 65.6 & 16.9 & 0.06 & 63.7 & 35.9 & 0.68 & 61.8 & 45.5 & 1.57 \\
\hline NAM_M_M & 10.9 & 0.62 & 0.39 & 34.7 & 18.2 & 0.67 & 55.2 & 36.1 & 1.12 \\
\hline NAM_T_Y & 55.3 & 13.3 & 0.05 & 49.0 & 27.1 & 0.63 & 51.1 & 36.4 & 1.40 \\
\hline NAM_T_M & 24.1 & 8.4 & 0.57 & 28.4 & 12.9 & 0.58 & 45.3 & 26.2 & 0.88 \\
\hline
\end{tabular}

as in the DMIMS and E-PEACE cases (Fig. 18). WRF seems to capture this feature; however, NAM LBCs appear to overestimate the clearing (see the appendix). Similar to E-PEACE, NAM LBCs capture more accurately the northern extent of the cloud deck (see the appendix). The stratus to stratocumulus transition is offset to the north in all of the simulations. Interestingly, for the NARR forcing simulations, the MYJ PBL scheme shows better cloud coverage near the coast. As in the other two cases, the Thompson microphysics simulations generally produce lower cloud LWPs. It is difficult to visually choose one configuration, but the simulations with NARR forcing, YSU PBL, and Morrison/Thompson adequately replicate the cloud field, especially because they show higher LWPs at the southern edge of the model domain, whereas the MYJ simulations show much lower LWPs in this region.

\section{Summary and conclusions}

In this study, we first investigate the possible impact of marine and continental aerosol sources on CTD clouds due to the associated large-scale meteorological patterns. These results motivate the second portion of the study in which we present in situ aircraft measurements and satellite retrievals, in addition to output from the WRF Model, for three well-observed CTD events offshore California. The model is evaluated using a set of numerical simulations that test the sensitivity of the model to various configurations involving forcing conditions and physics parameterizations. The main findings are as follows:

- For each of the three cases examined here, the synoptic-scale meteorological conditions leading to the inception of a CTD are similar and may be characterized by a relatively strong SLP gradient in addition to enhanced offshore flow and subsidence above the MBL. These characteristics are most notable in the DMIMS case.

- Backward trajectories generated using HYSPLIT reveal the potential influence from continental regions on the marine layer: air parcels ending at $100 \mathrm{~m}$ MSL (in the MBL) nearshore show weak interaction with continental sources, while those ending at $1000 \mathrm{~m}$ MSL (above the MBL) show strong interaction with continental sources.

- Cloud water samples from E-PEACE and BOAS suggest that shipping emissions, continental sources, or both impact CTD clouds. During the E-PEACE CTD, chloride depletion appears to occur over a several day period. Ammonium concentrations, in addition to ammonium/NSS sulfate and ammonium/nitrate ion ratios, are enhanced during the BOAS CTD. Concentrations of metals-specifically, manganese and iron-are much greater than normal for both EPEACE and BOAS during the CTD cases.

- Simulations using the MYJ PBL scheme consistently produce less cloud than those using the YSU PBL scheme. We find that the macrophysical cloud properties may be affected primarily by the choice of PBL parameterization rather than the choice of microphysics parameterization.

- Daytime MODIS retrievals suggest that the WRF simulations-especially those using NAM forcinghave an issue properly representing the cloud coverage and cloud LWP field near the coastline.

- Sensitivity simulations that test the impact of the driving model suggest that LBCs may influence the model solution more than ICs (see the appendix).

The results presented here show that, when using the YSU PBL parameterization, the cloud fields associated with the DMIMS, E-PEACE, and BOAS CTDs are typically represented better than when using the MYJ PBL parameterization. We hypothesize 
that YSU is superior to MYJ in these particular events because the fundamental vertical mixing approach used in the nonlocal (YSU PBL) scheme allows relatively large BL eddies to dominate scalar exchange. Also, the MBL is represented more physically in the YSU scheme because it explicitly treats entrainment. While our results corroborate prior results that examine the effect of PBL parameterizations on stratiform clouds (e.g., Holtslag and Boville 1993; Martin et al. 2000), additional cases should be investigated to support this hypothesis in the context of CTDs. Regardless of the PBL parameterization, issues still remain in WRF with respect to vertical mixing and excess cloud LWC.

Future modeling efforts should probe the effects of various physical processes on CTD cloud evolution. More specifically, model representation of cloud microphysical processes such as droplet sedimentation, autoconversion, accretion, and self-collection should be the focus of future work. Also, the predicted particle properties (P3; Morrison and Milbrandt 2015) and Thompson aerosolaware (Thompson and Eidhammer 2014) schemes may be used to address the impact of predicting, rather than prescribing, cloud droplet number concentration. More broadly, the roles of entrainment, turbulence, and radiation in CTD cloud environments should be explored.

Acknowledgments. The authors are grateful for support in part from the State of Wyoming and the Carlton R. Barkhurst Fellowship (TWJ), NCAR through the National Science Foundation (GT), the National Science Foundation through Grant AGS-1439515 (DAR), the Office of Naval Research through Grant N00014-17-12719 (JHS), the Office of Naval Research through Grants N00014-10-1-0811 and N00014-16-1-2567 (AS), and the Department of Energy through Grant DE-SC0016354 (ZJL). We thank the three anonymous reviewers, in addition to the editor, whose valuable comments have improved the manuscript. We would also like to acknowledge high-performance computing support from Cheyenne (doi: 10.5065/D6RX99HX) provided by NCAR's Computational and Information Systems Laboratory and sponsored by the National Science Foundation. The authors gratefully acknowledge the NOAA Air Resources Laboratory (ARL) for the provision of the HYSPLIT transport and dispersion model and READY website (http://www.ready.noaa.gov) used in this publication.

\section{APPENDIX}

\section{Influence of the Driving Model}

To examine the impact of ICs versus LBCs on the model results presented herein, two simulations are conducted for each of the three CTD cases. For the first sensitivity simulation, we force the model using ICs from NAM and LBCs from NARR. Then, we swap the sources of the ICs and LBCs for the second sensitivity simulation (i.e., ICs and LBCs are from NARR and NAM, respectively). The model configuration for these simulations is the same as that used for all of the other simulations presented in the study; however, here we select the Thompson microphysics and the YSU PBL schemes. Conducting these two sensitivity simulations for each CTD event allows us to determine which aspect of the driving model likely has a stronger impact on the reported results nearly 3 days after initialization.

Figure A1 shows the UWKA vertical sawtooth flight track from the DMIMS case as well as two of the original simulations and the corresponding sensitivity simulations. Observations (Fig. A1a), and model output from simulations using NARR (Fig. A1b) and NAM (Fig. A1c) forcing here are reproduced from Figs. A1a, A1d, and A1h, respectively, from Fig. 10. Neither the simulation using NAM ICs/NARR LBCs (Fig. A1d) nor the simulation using NARR ICs/NAM LBCs (Fig. A1e) produce output that is very similar to the simulation using either NARR or NAM forcing. However, the cloud field from the NAM ICs/NARR LBCs simulation looks more similar to that in the NAM forcing simulation than the NARR forcing simulation. Interestingly, this combination produces a relatively deep cloud field that is most similar to the observations. Also, the NARR ICs/NAM LBCs simulation produces minimal clouds; additional analysis shows that this is due to the lack of horizontal cloud coverage in this simulation (not shown).

The Twin Otter flight legs from the E-PEACE case with two of the original model simulations and the corresponding sensitivity simulations are shown in Fig. A2. Once again, observations (Fig. A2a), and model output from simulations using NARR (Fig. A2b) and NAM (Fig. A2c) forcing here are reproduced from Figs. A2a, A2d, and A2h, respectively, from Fig. 11. While there are some minor differences between the simulations, the wind fields from the NAM ICs/NARR LBCs (Fig. A2d) and the NARR ICs/NAM LBCs (Fig. A2e) configurations are most similar to the simulations using NARR and NAM forcing, respectively. Moreover, the LWC values from the NAM ICs/NARR LBCs and NARR ICs/NAM LBCs configurations are generally closer to those from the NARR and NAM forcing configurations, respectively.

Last, for the BOAS case, we show the MODIS retrievals compared to two of the original model simulations and the corresponding sensitivity simulations 

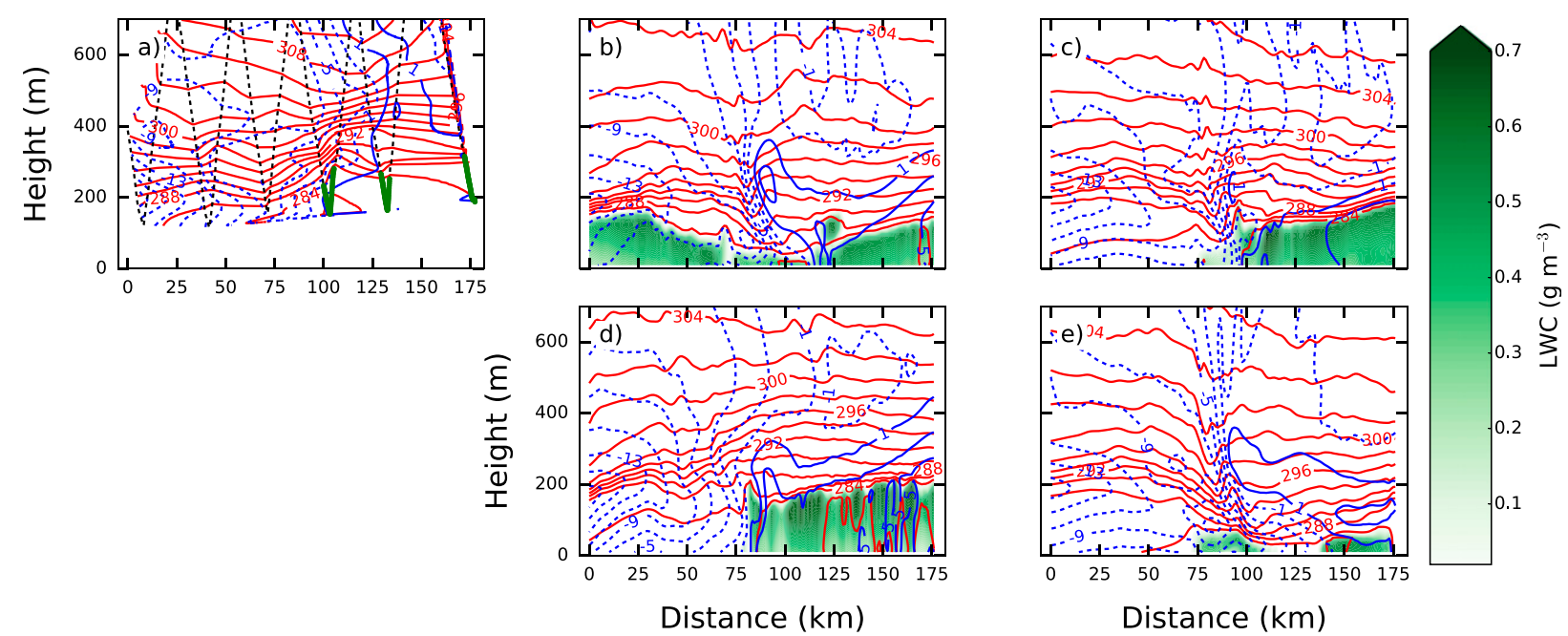

FIG. A1. As in Fig. 10, but showing (a) UWKA observations, and WRF output from various configurations: (b) NARR_T_Y, (c) NAM_T_Y, (d) [NAM ICs/NARR LBCs]_T_Y, and (e) [NARR ICs/NAM LBCs]_T_Y.

(Fig. A3). As in the previous two figures, observations (Fig. A3a), and model output from simulations using NARR (Fig. A3b) and NAM (Fig. A3c) forcing here are reproduced from Figs. A3a, A3d, and A3h, respectively, from Fig. 18. Overall, the LBCs appear to control the horizontal cloud extent, as the simulations using NARR forcing and NAM ICs/NARR LBCs (Fig. A3d), and those using NAM forcing and NARR ICs/NAM LBCs (Fig. A3e), are quite similar. One notable feature that remains consistent between the simulations using
NARR forcing and NARR ICs/NAM LBCs is the small region of high LWP near $36.0^{\circ} \mathrm{N}, 122.0^{\circ} \mathrm{W}$. The WRF results for the E-PEACE case also produce this feature (see Fig. 17), and our driving model sensitivity tests for that case also yield a qualitatively similar result (not shown).

The sensitivity simulations presented here yield some interesting results. The DMIMS comparison suggests that the ICs may influence the model solution more than the LBCs, although neither aspect of the driving

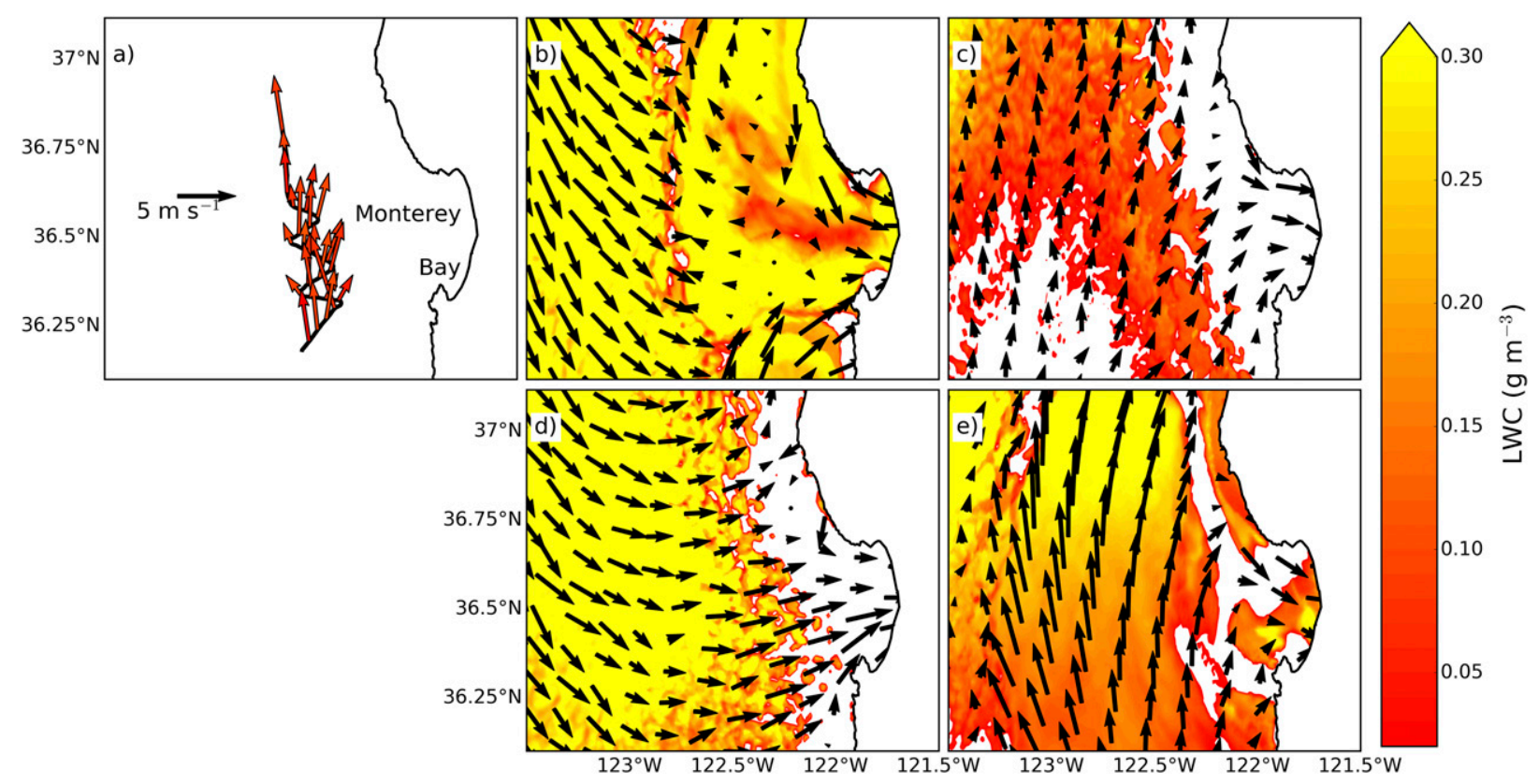

FIG. A2. As in Fig. 11, but showing (a) Twin Otter observations, and WRF output from various configurations: (b) NARR_T_Y, (c) NAM_T_Y, (d) [NAM ICs/NARR LBCs]_T_Y, and (e) [NARR ICs/NAM LBCs]_T_Y. 

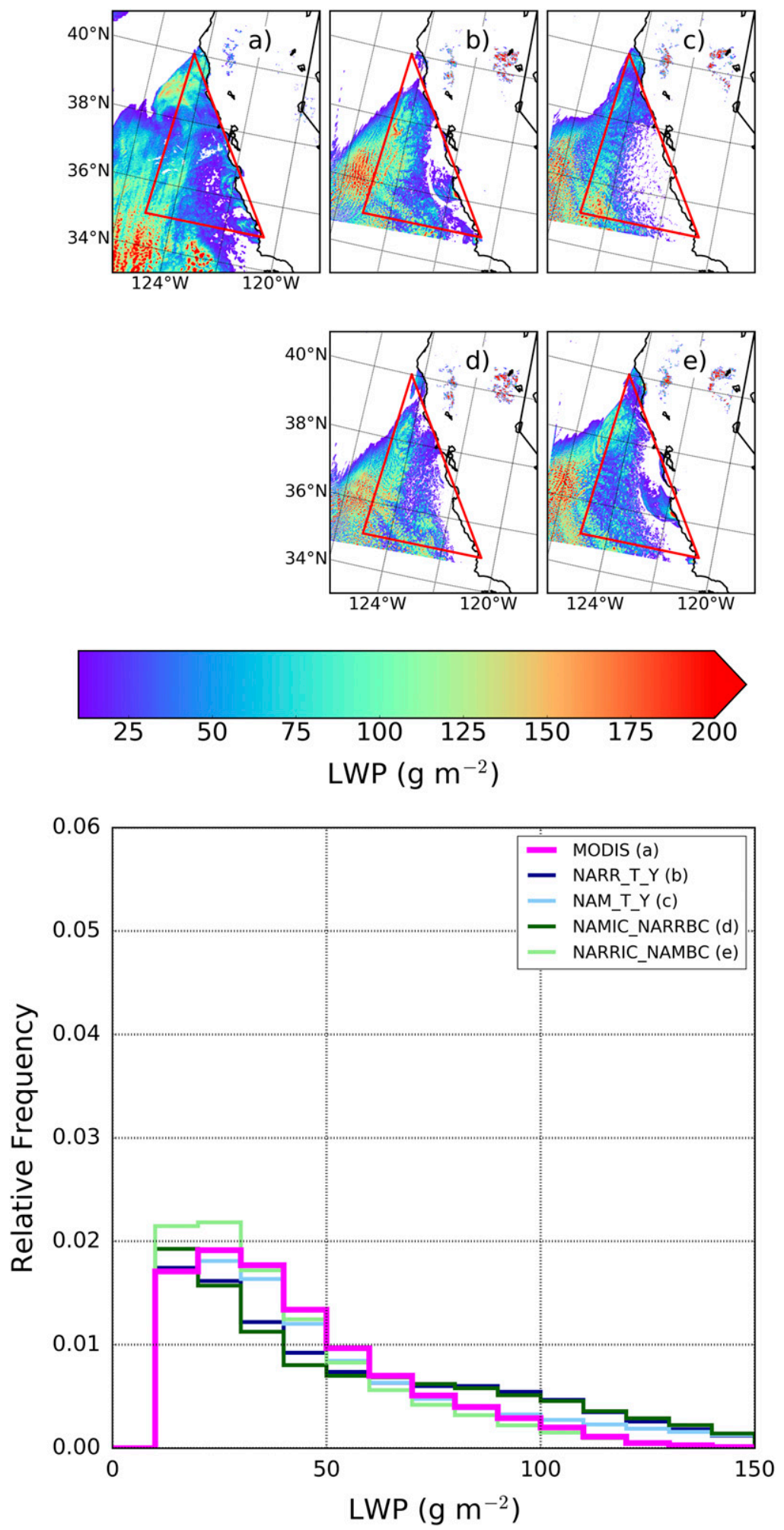

FIG. A3. As in Fig. 18, but showing (a) MODIS LWP, and WRF output from various configurations: (b) NARR_T_Y, (c) NAM_T_Y, (d) [NAM ICs/NARR LBCs]_T_Y, and (e) [NARR ICs/NAM LBCs]_T_Y. 
model appears to dominate. For the E-PEACE case, the results indicate that the LBCs may influence the model solution more than the ICs. Analysis for the BOAS event shows that both the LBCs and ICs influence different characteristics of the stratiform clouds. While these results are inconclusive, they imply that future numerical modeling studies should focus on the impact of ICs versus LBCs in the context of MBL clouds.

\section{REFERENCES}

Abel, S. J., D. N. Walters, and G. Allen, 2010: Evaluation of stratocumulus cloud prediction in the Met Office forecast model during VOCALS-REx. Atmos. Chem. Phys., 10, 10 541-10 559, https://doi.org/10.5194/acp-10-10541-2010.

Ackerman, A. S., O. B. Toon, D. E. Stevens, A. J. Heymsfield, V. Ramanathan, and E. J. Welton, 2000: Reduction of tropical cloudiness by soot. Science, 288, 1042-1047, https://doi.org/ 10.1126/science.288.5468.1042.

Agrawal, H., Q. G. J. Malloy, W. A. Welch, J. W. Miller, and D. R. Cocker III, 2008: In-use gaseous and particulate matter emissions from a modern ocean going container vessel. Atmos. Environ., 42, 5504-5510, https://doi.org/ 10.1016/j.atmosenv.2008.02.053.

Albrecht, B. A., 1989: Aerosols, cloud microphysics, and fractional cloudiness. Science, 245, 1227-1230, https://doi.org/ 10.1126/science.245.4923.1227.

—, C. W. Fairall, D. W. Thomson, A. B. White, J. B. Snider, and W. H. Schubert, 1990: Surface-based remote sensing of the observed and the adiabatic liquid water content of stratocumulus clouds. Geophys. Res. Lett., 17, 89-92, https://doi.org/ 10.1029/GL017i001p00089.

Amiri-Farahani, A., R. J. Allen, D. Neubauer, and U. Lohmann, 2017: Impact of Saharan dust on North Atlantic marine stratocumulus clouds: Importance of the semidirect effect. Atmos. Chem. Phys., 17, 6305-6322, https://doi.org/10.5194/acp-176305-2017.

Andrejczuk, M., W. W. Grabowski, A. Gadian, and R. Burton, 2012: Limited-area modelling of stratocumulus over southeastern Pacific. Atmos. Chem. Phys., 12, 3511-3526, https:// doi.org/10.5194/acp-12-3511-2012.

Beardsley, R. C., C. E. Dorman, C. A. Friehe, L. K. Rosenfeld, and C. D. Winant, 1987: Local atmospheric forcing during the Coastal Ocean Dynamics Experiment: 1. A description of the marine boundary layer and atmospheric conditions over a Northern California upwelling region. J. Geophys. Res., 92, 1467-1488, https://doi.org/10.1029/ JC092iC02p01467.

Beheng, K. D., 1994: A parameterization of warm cloud microphysical conversion processes. Atmos. Res., 33, 193-206, https://doi.org/10.1016/0169-8095(94)90020-5.

Berry, E. X., and R. L. Reinhardt, 1974: An analysis of cloud droplet growth by collection. Part II: Single initial distributions. J. Atmos. Sci., 31, 2127-2135, https://doi.org/ 10.1175/1520-0469(1974)031<2127:AAOCDG > 2.0.CO;2.

Bond, N. A., C. F. Mass, and J. E. Overland, 1996: Coastally trapped wind reversals along the United States West Coast during the warm season. Part I: Climatology and temporal evolution. Mon. Wea. Rev., 124, 430-445, https://doi.org/ 10.1175/1520-0493(1996)124<0430:CTWRAT>2.0.CO;2.
Boucher, O., and Coauthors, 2013: Clouds and aerosols. Climate Change 2013: The Physical Science Basis, T. F. Stocker et al., Eds., Cambridge University Press, 571-657.

Braun, R. A., and Coauthors, 2017: Impact of wildfire emissions on chloride and bromide depletion in marine aerosol particles. Environ. Sci. Technol., 51, 9013-9021, https://doi.org/10.1021/ acs.est.7b02039.

Brenguier, J.-L., and Coauthors, 2000: An overview of the ACE-2 CLOUDYCOLUMN closure experiment. Tellus, 52B, 815827, https://doi.org/10.1034/j.1600-0889.2000.00047.x.

_- F. Burnet, and O. Geoffroy, 2011: Cloud optical thickness and liquid water path-Does the $k$ coefficient vary with droplet concentration? Atmos. Chem. Phys., 11, 9771-9786, https://doi.org/10.5194/acp-11-9771-2011.

Chen, G., W. Wang, and J. Chen, 2015: Aerosol-stratocumulusradiation interactions over the southeast Pacific. J. Atmos. Sci., 72, 2612-2621, https://doi.org/10.1175/JAS-D-14-0319.1.

Chen, Y.-C., L. Xue, Z. J. Lebo, H. Wang, R. M. Rasmussen, and J. H. Seinfeld, 2011: A comprehensive numerical study of aerosol-cloud-precipitation interactions in marine stratocumulus. Atmos. Chem. Phys., 11, 9749-9769, https://doi.org/ 10.5194/acp-11-9749-2011.

Coggon, M. M., and Coauthors, 2012: Ship impacts on the marine atmosphere: Insights into the contribution of shipping emissions to the properties of marine aerosol and clouds. Atmos. Chem. Phys., 12, 8439-8458, https://doi.org/10.5194/acp-12-8439-2012.

Crosbie, E., and Coauthors, 2016: Stratocumulus cloud clearings and notable thermodynamic and aerosol contrasts across the clear-cloudy interface. J. Atmos. Sci., 73, 1083-1099, https:// doi.org/10.1175/JAS-D-15-0137.1.

Dorman, C. E., 1985: Evidence of kelvin waves in California's marine layer and related eddy generation. Mon. Wea. Rev., 113, 827-839, https://doi.org/10.1175/1520-0493(1985)113<0827:EOKWIC> 2.0.CO;2.

Fewings, M. R., L. Washburn, C. E. Dorman, C. Gotschalk, and K. Lombardo, 2016: Synoptic forcing of wind relaxations at Pt. Conception, California. J. Geophys. Res. Oceans, 121, 5711-5730, https://doi.org/10.1002/2016JC011699.

Flynn, K. R., M. R. Fewings, C. Gotschalk, and K. Lombardo, 2017: Large-scale anomalies in sea-surface temperature and air-sea fluxes during wind relaxation events off the United States West Coast in summer. J. Geophys. Res. Oceans, 122, 25742594, https://doi.org/10.1002/2016JC012613.

Furutani, H., J. Jung, K. Miura, A. Takami, S. Kato, Y. Kajii, and M. Uematsu, 2011: Single-particle chemical characterization and source apportionment of iron-containing atmospheric aerosols in Asian outflow. J. Geophys. Res., 116, D18204, https://doi.org/10.1029/2011JD015867.

Gerber, H., B. G. Arends, and A. S. Ackerman, 1994: New microphysics sensor for aircraft use. Atmos. Res., 31, 235-252, https://doi.org/10.1016/0169-8095(94)90001-9.

Hegg, D. A., and P. V. Hobbs, 1986: Studies of the mechanisms and rate with which nitrogen species are incorporated into cloud water and precipitation. Coordinating Research Council Second Annual Rep. on Project CAPA-21-80.

Holtslag, A. A., and B. A. Boville, 1993: Local versus nonlocal boundary-layer diffusion in a global climate model. J. Climate, 6, 1825-1842, https://doi.org/10.1175/1520-0442(1993)006<1825: LVNBLD $>2.0 . \mathrm{CO} ; 2$.

Hong, S.-Y., Y. Noh, and J. Dudhia, 2006: A new vertical diffusion package with an explicit treatment of entrainment processes. Mon. Wea. Rev., 134, 2318-2341, https://doi.org/ 10.1175/MWR3199.1. 
Iacono, M. J., J. S. Delamere, E. J. Mlawer, M. W. Shephard, S. A. Clough, and W. D. Collins, 2008: Radiative forcing by longlived greenhouse gases: Calculations with the AER radiative transfer models. J. Geophys. Res., 113, D13103, https://doi.org/ 10.1029/2008JD009944.

Janjić, Z. I., 1994: The step-mountain eta coordinate model: Further developments of the convection, viscous sublayer, and turbulence closure schemes. Mon. Wea. Rev., 122, 927-945, https://doi.org/ 10.1175/1520-0493(1994)122<0927:TSMECM > 2.0.CO;2.

Jiang, X., T. L. Kubar, S. Wong, W. S. Olson, and D. E. Waliser, 2014: Modulation of marine low clouds associated with the tropical intraseasonal variability over the eastern Pacific. J. Climate, 27, 5560-5574, https://doi.org/10.1175/JCLI-D-1300569.1.

Juliano, T. W., Z. J. Lebo, G. Thompson, and D. A. Rahn, 2019: A new perspective on coastally trapped disturbances using data from the satellite era. Bull. Amer. Meteor. Soc., 100, 631-651, https://doi.org/10.1175/BAMS-D-18-0002.1.

Khairoutdinov, M. F., and Y. L. Kogan, 2000: A new cloud physics parameterization in a large-eddy simulation model of marine stratocumulus. Mon. Wea. Rev., 128, 229-243, https://doi.org/ 10.1175/1520-0493(2000)128<0229:ANCPPI > 2.0.CO;2.

Kim, C. K., and S. S. Yum, 2017: Turbulence in marine fog. Marine Fog: Challenges and Advancements in Observations, Modeling, and Forecasting, D. Koraciin and C. E. Dorman, Eds., Springer, 245-271.

Klein, S. A., and D. L. Hartmann, 1993: The seasonal cycle of low stratiform clouds. J. Climate, 6, 1587-1606, https://doi.org/ 10.1175/1520-0442(1993)006<1587:TSCOLS > 2.0.CO;2.

Kloesel, K. A., 1992: Marine stratocumulus cloud clearing episodes observed during FIRE. Mon. Wea. Rev., 120, 565-578, https:// doi.org/10.1175/1520-0493(1992)120<0565:MSCCEO>2.0.CO;2.

Koračin, D., and C. E. Dorman, Eds., 2017: Marine Fog: Challenges and Advancements in Observations, Modeling, and Forecasting. Springer, $537 \mathrm{pp}$.

Lee, H., and J. Baik, 2017: A physically based autoconversion parameterization. J. Atmos. Sci., 74, 1599-1616, https://doi.org/ 10.1175/JAS-D-16-0207.1.

Mardi, A. H., and Coauthors, 2018: Biomass burning plumes in the vicinity of the California coast: Airborne characterization of physicochemical properties, heating rates, and spatiotemporal features. J. Geophys. Res. Atmos., 123, 13 560-13 582, https:// doi.org/10.1029/2018JD029134.

Martin, G. M., M. Bush, A. R. Brown, A. P. Lock, and R. N. Smith, 2000: A new boundary layer mixing scheme. Part II: Tests in climate and mesoscale models. Mon. Wea. Rev., 128, 3200-3217, https://doi.org/ 10.1175/1520-0493(2000)128<3200:ANBLMS > 2.0.CO;2.

Mass, C. F., and N. A. Bond, 1996: Coastally trapped wind reversals along the United States West Coast during the warm season. Part II: Synoptic evolution. Mon. Wea. Rev., 124, 446-461, https:// doi.org/10.1175/1520-0493(1996)124<0446:CTWRAT>2.0.CO;2. , and W. J. Steenburgh, 2000: An observational and numerical study of an orographically trapped wind reversal along the West Coast of the United States. Mon. Wea. Rev., 128, 2363-2397, https://doi.org/10.1175/1520-0493(2000)128<2363: AOANSO $>2.0 . \mathrm{CO} ; 2$.

Maudlin, L. C., Z. Wang, H. H. Jonsson, and A. Sorooshian, 2015: Impact of wildfires on size-resolved aerosol composition at a coastal California site. Atmos. Environ., 119, 59-68, https:// doi.org/10.1016/j.atmosenv.2015.08.039.

Mesinger, F., and Coauthors, 2006: North American Regional Reanalysis. Bull. Amer. Meteor. Soc., 87, 343-360, https:// doi.org/10.1175/BAMS-87-3-343.
Mocko, D. M., and W. R. Cotton, 1995: Evaluation of fractional cloudiness parameterizations for use in a mesoscale model. J. Atmos. Sci., 52, 2884-2901, https://doi.org/10.1175/15200469(1995)052<2884:EOFCPF>2.0.CO;2.

Moeng, C., and P. P. Sullivan, 1994: A comparison of shear- and buoyancy-driven planetary boundary layer flows. J. Atmos. Sci., 51, 999-1022, https://doi.org/10.1175/1520-0469(1994) $051<0999: \mathrm{ACOSAB}>2.0 . \mathrm{CO} ; 2$.

Morrison, H., and J. A. Milbrandt, 2015: Parameterization of cloud microphysics based on the prediction of bulk ice particle properties. Part I: Scheme description and idealized tests. J. Atmos. Sci., 72, 287-311, https://doi.org/10.1175/JAS-D-140065.1.

_ J. A. Curry, and V. I. Khvorostyanov, 2005: A new doublemoment microphysics parameterization for application in cloud and climate models. Part I: Description. J. Atmos. Sci., 62, 1665-1677, https://doi.org/10.1175/JAS3446.1.

Neiburger, M., D. S. Johnson, and C. W. Chien, 1961: Studies of the structure of the atmosphere over the eastern Pacific ocean in the summer. The Inversion over the Eastern North Pacific Ocean, University of California Press, 1-94.

Nuss, W. A., and Coauthors, 2000: Coastally trapped wind reversals: Progress toward understanding. Bull. Amer. Meteor. Soc., 81, 719-743, https://doi.org/10.1175/1520-0477(2000) 081<0719:CTWRPT>2.3.CO;2.

Parish, T. R., 2000: Forcing of the summertime low-level jet along the California coast. J. Appl. Meteor., 39, 2421-2433, https://doi.org/ 10.1175/1520-0450(2000)039<2421:FOTSLL > 2.0.CO;2.

—, D. A. Rahn, and D. Leon, 2008: Aircraft observations of a coastally trapped wind reversal off the California coast. Mon. Wea. Rev., 136, 644-663, https://doi.org/ 10.1175/2007MWR2199.1.

Pawlowska, H., and J.-L. Brenguier, 2003: An observational study of drizzle formation in stratocumulus clouds for general circulation model (GCM) parameterizations. J. Geophys. Res., 108, 8630, https://doi.org/10.1029/2002JD002679.

Prabhakar, G., B. Ervens, Z. Wang, L. C. Maudlin, M. M. Coggon, H. H. Jonsson, J. H. Seinfeld, and A. Sorooshian, 2014: Sources of nitrate in stratocumulus cloud water: Airborne measurements during the 2011 E-PEACE and $2013 \mathrm{NiCE}$ studies. Atmos. Environ., 97, 166-173, https://doi.org/10.1016/ j.atmosenv.2014.08.019.

Rahn, D. A., and T. R. Parish, 2008: A study of the forcing of the 22-25 June 2006 coastally trapped wind reversal based on numerical simulations and aircraft observations. Mon. Wea. Rev., 136, 4687-4708, https://doi.org/10.1175/ 2008MWR2361.1.

— , and R. Garreaud, 2010: Marine boundary layer over the subtropical southeast Pacific during VOCALS-REx-Part 1: Mean structure and diurnal cycle. Atmos. Chem. Phys., 10, 4491-4506, https://doi.org/10.5194/acp-10-4491-2010.

— , and T. R. Parish, 2010: Cessation of the 22-25 June 2006 coastally trapped wind reversal. J. Appl. Meteor. Climatol., 49, 1412-1428, https://doi.org/10.1175/2010JAMC2242.1.

__, _ _ , and D. Leon, 2016: Observations of large wind shear above the marine boundary layer near Point Buchon, California. J. Atmos. Sci., 73, 3059-3077, https://doi.org/ 10.1175/JAS-D-15-0363.1.

Randall, D. A., J. A. Coakley, D. H. Lenschow, C. W. Fairall, and R. A. Kropfli, 1984: Outlook for research on subtropical marine stratification clouds. Bull. Amer. Meteor. Soc., 65 , 1290-1301, https://doi.org/10.1175/1520-0477(1984)065<1290: OFROSM $>2.0 . \mathrm{CO} ; 2$. 
Rutledge, S. A., and P. Hobbs, 1983: The mesoscale and microscale structure and organization of clouds and precipitation in midlatitude cyclones. VIII: A model for the "seeder-feeder" process in warm-frontal rainbands. J. Atmos. Sci., 40, 1185-1206, https://doi.org/10.1175/1520-0469(1983)040<1185: TMAMSA $>2.0 . \mathrm{CO} ; 2$.

Schubert, W. H., 1976: Experiments with Lilly's cloud-topped mixed layer model. J. Atmos. Sci., 33, 436-446, https://doi.org/10.1175/ 1520-0469(1976)033<0436:EWLCTM>2.0.CO;2.

Seinfeld, J. H., and S. N. Pandis, 2006: Atmospheric Chemistry and Physics. 3rd ed. Wiley, 1152 pp.

Snider, J. R., D. Leon, and Z. Wang, 2017: Droplet concentration and spectral broadening in southeast Pacific stratocumulus clouds. J. Atmos. Sci., 74, 719-749, https://doi.org/10.1175/ JAS-D-16-0043.1.

Sorooshian, A., and Coauthors, 2018: A multi-year data set on aerosol-cloud-precipitation-meteorology interactions for marine stratocumulus clouds. Sci. Data, 5 180026, https://doi.org/ 10.1038/SDATA.2018.26.

Srivastava, R. C., and J. L. Coen, 1992: New explicit equations for the accurate calculation of the growth and evaporation of hydrometeors by the diffusion of water vapor. J. Atmos. Sci., 49, 1643-1651, https://doi.org/10.1175/1520-0469(1992) 049<1643:NEEFTA $>2.0$. CO 2 .

Stein, A. F., R. R. Draxler, G. D. Rolph, B. J. B. Stunder, M. D. Cohen, and F. Ngan, 2015: NOAA's HYSPLIT atmospheric transport and dispersion modeling system. Bull. Amer. Meteor. Soc., 96, 2059-2077, https://doi.org/10.1175/BAMS-D-1400110.1 .

Sundqvist, H., E. Berge, and J. E. Kristjánsson, 1989: Condensation and cloud parameterization studies with a mesoscale numerical weather prediction model. Mon. Wea. Rev., 117, 1641-1657, https://doi.org/10.1175/1520-0493(1989)117<1641: CACPSW $>2.0 . \mathrm{CO} ; 2$.

Tewari, M., and Coauthors, 2004: Implementation and verification of the unified NOAH land surface model in the WRF Model. 20th Conf. on Weather Analysis and Forecasting/16th Conf. on Numerical Weather Prediction, Seattle, WA, Amer. Meteor. Soc., 11-15.

Thompson, G., and T. Eidhammer, 2014: A study of aerosol impacts on clouds and precipitation development in a large winter cyclone. J. Atmos. Sci., 71, 3636-3658, https://doi.org/ 10.1175/JAS-D-13-0305.1.

—, P. R. Field, R. M. Rasmussen, and W. D. Hall, 2008: Explicit forecasts of winter precipitation using an improved bulk microphysics scheme. Part II: Implementation of a new snow parameterization. Mon. Wea. Rev., 136, 5095-5115, https:// doi.org/10.1175/2008MWR2387.1.

Thompson, W. T., S. D. Burke, and J. Lewis, 2005: Fog and low clouds in a coastally trapped disturbance. J. Geophys. Res., 110, D18213, https://doi.org/10.1029/2004JD005522.

Twomey, S., 1977: The influence of pollution on the shortwave albedo of clouds. J. Atmos. Sci., 34, 1149-1152, https://doi.org/ 10.1175/1520-0469(1977)034<1149:TIOPOT>2.0.CO;2.

Verlinde, J., and W. R. Cotton, 1993: Fitting microphysical observations of nonsteady convective clouds to a numerical model: An application of the adjoint technique of data assimilation to a kinematic model. Mon. Wea. Rev., 121, 2776-2793, https://doi.org/10.1175/1520-0493(1993)121<2776: FMOONC $>2.0 . \mathrm{CO} ; 2$.

—- P. J. Flatau, and W. R. Cotton, 1990: Analytical solutions to the collection growth equation: Comparison with approximate methods and application to the cloud microphysics parameterization schemes. J. Atmos. Sci., 47, 28712880, https://doi.org/10.1175/1520-0469(1990)047<2871: ASTTCG $>2.0 . \mathrm{CO} ; 2$.

Wang, S., and Coauthors, 2011: A regional real-time forecast of marine boundary layers during VOCALS-REx. Atmos. Chem. Phys., 11, 421-437, https://doi.org/10.5194/acp-11-421-2011.

Wang, X., 2010: Incorporating ensemble covariance in the gridpoint statistical interpolation variational minimization: A mathematical framework. Mon. Wea. Rev., 138, 2990-2995, https://doi.org/10.1175/2010MWR3245.1.

Wood, R., 2012: Stratocumulus clouds. Mon. Wea. Rev., 140, 2373-2423, https://doi.org/10.1175/MWR-D-11-00121.1.

_ path in marine low cloud: The importance of mesoscale cellular convection. J. Climate, 19, 1748-1764, https://doi.org/ 10.1175/JCLI3702.1.

Wyant, M. C., and Coauthors, 2007: A single-column model intercomparison of a heavily drizzling stratocumulus-topped boundary layer. J. Geophys. Res., 112, D24204, https:// doi.org/10.1029/2007JD008536.

—_, and Coauthors, 2010: The PreVOCA experiment: Modeling the lower troposphere in the Southeast Pacific. Atmos. Chem. Phys., 10, 4757-4774, https://doi.org/10.5194/acp-104757-2010.

— and aerosols in the marine boundary layer during VOCALS: The VOCA intercomparison. Atmos. Chem. Phys., 15, 153172, https://doi.org/10.5194/acp-15-153-2015.

Xiao, Q., and Coauthors, 2018: Characteristics of marine shipping emissions at berth: Profiles for particulate matter and volatile organic compounds. Atmos. Chem. Phys. 18, 9527-9545, https://doi.org/10.5194/acp-18-9527-2018.

Yamaguchi, T., G. Feingold, and V. E. Larson, 2017: Framework for improvement by vertical enhancement: A simple approach to improve representation of low and high-level clouds in large-scale models. J. Adv. Model. Earth Syst., 9, 627-646, https://doi.org/10.1002/2016MS000815.

Yang, Q., and Coauthors, 2011: Assessing regional scale predictions of aerosols, marine stratocumulus, and their interactions during VOCALS-REx using WRF-Chem. Atmos. Chem. Phys., 11, 11 951-11 975, https://doi.org/10.5194/acp-11-119512011.

Yu, H., and Coauthors, 2006: A review of measurement-based assessments of the aerosol direct radiative effect and forcing. Atmos. Chem. Phys., 6, 613-666, https://doi.org/10.5194/acp-6613-2006.

Zhu, P., and Coauthors, 2005: Intercomparison and interpretation of single-column model simulations of a nocturnal stratocumulus-topped marine boundary layer. Mon. Wea. Rev., 133, 2741-2758, https://doi.org/10.1175/MWR2997.1. 